\title{
Methanol-mediated Electrosynthesis of Ammonia
}

Yongwen Ren, Chang Yu*, Xiaotong Han, Xinyi Tan, Qianbing Wei, Wenbin Li, Yingnan Han, Le

Yang, Jieshan Qiu*

State Key Laboratory of Fine Chemicals, Liaoning Key Lab for Energy Materials and Chemical

Engineering, School of Chemical Engineering, Dalian University of Technology, Dalian 116024, China

Email: chang.yu@dlut.edu.cn (C.Y.); jqiu@dlut.edu.cn (J.Q.) 
Table of Contents

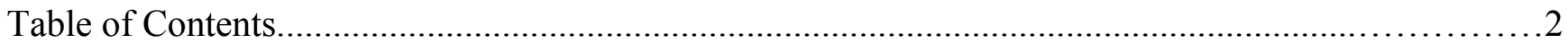

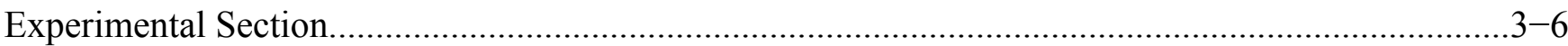

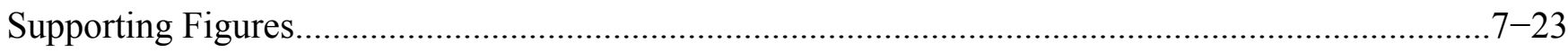

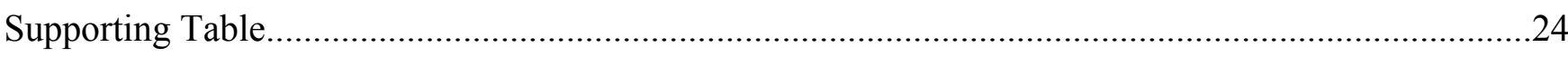

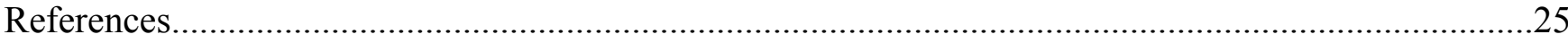




\section{Experimental Section.}

\subsection{Synthesis of $\mathrm{FeOOH} / \mathrm{CNTs}$.}

The $\mathrm{FeOOH}$ was fabricated on multiwalled carbon nanotubes (CNTs) via a facile solution impregnation method. ${ }^{1-2}$ For a typical run, the CNTs was first oxidized by a plasma system (PCE-6 PLASMA CLEANER) for 10 min with a power of $19.6 \mathrm{~W}$ and a pressure of $50 \mathrm{~Pa}$ in oxygen atmosphere. ${ }^{3}$ After that, $12 \mathrm{mg}$ of the oxidized CNTs was dispersed into $120 \mathrm{~mL}$ of deionized water with the ultrasonic assistance. Then $0.65 \mathrm{~g}$ of $\mathrm{FeCl}_{3} \cdot 6 \mathrm{H}_{2} \mathrm{O}(99 \%$, Aladdin Chemistry) was added into above solution. The resulting solution was sealed and stirred for $36 \mathrm{~h}$ at room temperature. After reaction, the resultant $\mathrm{FeOOH} / \mathrm{CNTs}$ was washed with excessive deionized water and ethanol respectively, and was dried at room temperature.

\subsection{Materials characterization.}

The morphology of the as-made catalyst was observed by scanning electron microscopy (SEM, QUANTA 450, $20 \mathrm{kV}$ ) and transmission electron microscopy (TEM, Tecnai G220). The structure of the catalyst was investigated by X-ray diffraction (XRD, D/MAX-2400) using $\mathrm{Cu}$ K $\alpha$ radiation $(\lambda=1.5406$ $\AA$ ). The electron paramagnetic resonance (EPR) measurement was accomplished on a Bruker A200 EPR spectrometer at the room temperature with the micro frequency at $9.86 \mathrm{GHz}$. X-ray photoelectron spectroscopy (XPS, Thermo ESCALAB 250) with Al Ka X-ray radiation was performed to gain the chemical compositions of the catalyst.

\subsection{Cathode preparation.}

Typically, a homogeneous ink of catalyst was prepared by dispersing $4 \mathrm{mg}$ of catalyst into the mixed solution of $760 \mu \mathrm{L}$ of anhydrous ethanol, $200 \mu \mathrm{L}$ of deionized water, and $40 \mu \mathrm{L}$ of Nafion solution (Alfa Aesar, $5 \mathrm{wt} \%$ ) with the sonication assistance of $30 \mathrm{~min}$. Subsequently, $50 \mu \mathrm{L}$ of catalyst ink was loaded onto a carbon paper electrode with an area of $1 \times 1 \mathrm{~cm}^{2}$ and dried under ambient temperature. The mass loading of catalyst on carbon paper was calculated to be $0.2 \mathrm{mg} \mathrm{cm}^{-2}$.

\subsection{Electrochemical measurements.}

The electrochemical experiments were carried out on a $\mathrm{CHI} 760 \mathrm{E}$ electrochemistry workstation in a three-electrode configuration, where the counter and reference electrodes were Pt foil $\left(1 \times 1 \mathrm{~cm}^{2}\right)$ and $\mathrm{Ag} / \mathrm{AgCl}$ (saturated $\mathrm{KCl}$ electrolyte) electrode, respectively. All potentials were referred to the $\mathrm{Ag} / \mathrm{AgCl}$ electrode without further conversion. The cathode cell of the $\mathrm{H}$-type cell contained $30 \mathrm{~mL}$ of mixture of 
water and methanol (supreme anhydrous grade, 99.8\%, $\mathrm{H}_{2} \mathrm{O}$ content $<20 \mathrm{ppm}$ ) or ethanol (analytical reagent) or $n$-propanol (analytical reagent), etc., and the anode cell contained $30 \mathrm{~mL}$ of $\mathrm{KOH}$ aqueous solution $(1 \mathrm{M})$. To eliminate the effect of $\mathrm{NH}_{3}$ adsorption and release by the Nafion membrane on $\mathrm{NH}_{3}$ detection, the two chambers were separated by a piece of polyethylene film with a thickness of $2 \mathrm{~mm}$, and connected by a salt bridge filled with saturation $\mathrm{KCl}$ solution. ${ }^{4}$ The feeding $\mathrm{N}_{2}$ was purified through two acidic absorption cells (containing $1 \mathrm{M} \mathrm{HCl}$ solution and concentrated sulfuric acid, respectively). Before tests, the purified $\mathrm{N}_{2}$ was continuously purged into the electrolyte in cathode cell for 30 min with a flow rate of $20 \mathrm{~mL} \mathrm{~min}{ }^{-1}$. Subsequently, the NRR measurements were performed with continuous feeding of $\mathrm{N}_{2}\left(99.999 \%\right.$, Dalian Special Gases Co., Ltd.) at a gas flow rate of $10 \mathrm{~mL} \mathrm{~min}{ }^{-1}$. The potentiostatic tests were conducted for $2 \mathrm{~h}$ with $100 \% i R$-compensation at different potentials. The linear sweep voltammogram curves were recorded at a scan rate of $5 \mathrm{mV} \mathrm{s}^{-1}$. The $\mathrm{N}_{2}$ gas was replaced by Ar gas (99.999\%, Dalian Special Gases Co., Ltd.) to achieve the control experiments.

\subsection{Determination of ammonia.}

The produced $\mathrm{NH}_{3}$ was quantitatively determined through indophenol blue method and further confirmed by the ammonia selective electrode (ORION STAR A214, Thermo Fisher Scientific). ${ }^{5}$ As for indophenol blue method, $2 \mathrm{~mL}$ of product solution was mixed with $2 \mathrm{~mL}$ of $1 \mathrm{M} \mathrm{NaOH}$ solution containing $5 \mathrm{wt} \%$ salicylic acid and $5 \mathrm{wt} \%$ sodium citrate, $1 \mathrm{~mL}$ of $0.05 \mathrm{M} \mathrm{NaClO}$ (available chlorine $10-15 \%$, Macklin Reagent), and $0.2 \mathrm{~mL}$ of $1 \mathrm{wt} \%$ sodium nitroferricyanide dihydrate ( $>99 \%$, Aladdin Chemistry). After aging for $2 \mathrm{~h}$ at $25{ }^{\circ} \mathrm{C}$, the absorbance of above solution was measured by an Ultraviolet-visible (UV-Vis) spectrophotometer in the wavelength range of 550-800 $\mathrm{nm}$. The calibration curve of concentration-absorbance was obtained via fitting the ammonia concentrations of standard solutions $\left(0,0.5,1.0,2.0,4.0\right.$ and $\left.6.0 \mu \mathrm{g} \mathrm{mL} L^{-1}\right)$ versus corresponding absorbance values at 680 $\mathrm{nm}$. The resulted fitting curve $\left(y=0.33 x+0.04, R^{2}=0.9981\right)$ exhibited good linear relation, thus it can be utilized to determine the unknown ammonia concentration (Figure S6). All the ammonia concentrations were determined for three times.

The ammonia concentration was also verified by the method of ammonia selective electrode. In this method, the $0.1 \mathrm{M} \mathrm{KOH}$ solutions with the ammonia concentrations of $0.1,1$, and $10 \mu \mathrm{g} \mathrm{mL}{ }^{-1}$ were used as the standard solutions. Next, $0.5 \mathrm{~mL}$ of ionic strength adjustor (951211) was added to the standard solutions. Subsequently, corresponding potentials of the standard solutions were recorded under the mode of potential $(\mathrm{mV})$. The calibration curve was performed using $-\lg ($ ammonia concentration) versus corresponding potential value. The fitting curve $\left(\mathrm{y}=-59.7 \mathrm{x}+100.1, R^{2}=0.9996\right)$ exhibited good linear relation and excellent Nernstian response, which was employed to determine the unknown ammonia concentration (Figure S6). 


\section{6. ${ }^{15} \mathbf{N}_{2}$ isotopic labelling experiment.}

The control experiment of isotopically labeled ${ }^{15} \mathrm{~N}_{2}$ electroreduction was conducted with the focus of removing the ${ }^{14} \mathrm{~N}_{2}$ dissolved in the methanol-water electrolyte, and the detailed steps can be found in Figure S13. Specifically, $30 \mathrm{~mL}$ of methanol-water electrolyte was firstly poured into a home-made quartz tube connected to an oil pump. Then the quartz tube was placed into a Dewar flask filled with liquid nitrogen. After the electrolyte was entirely frozen, the oil pump was turned on and kept for $4 \mathrm{~h}$ to remove the ${ }^{14} \mathrm{~N}_{2}$ and $\mathrm{O}_{2}$ dissolved in the electrolyte. Subsequently, the quartz tube was sealed and transferred into a glovebox filled with Ar gas. The pretreated electrolyte was poured into the H-type cell in the glovebox under the protection of Ar gas. Next, the H-type cell was connected to a $\mathrm{NH}_{3}$ absorption cell $(1 \mathrm{M} \mathrm{HCl})$ and an air pocket filled with ${ }^{15} \mathrm{~N}_{2}$ gas $(99 \%$, Shanghai Engineering Research Center of Stable Isotope). Finally, the sealed H-type cell was taken out from the glovebox and then the potentiostatic test was carried out at $-1.2 \mathrm{~V} v s \mathrm{Ag} / \mathrm{AgCl}$ under ${ }^{15} \mathrm{~N}_{2}$ atmosphere.

After electrolysis, the electrolyte was concentrated by a rotatory evaporator, resulting in the formation of ammonium chloride. Then the salts were dissolved in $1 \mathrm{~mL}$ of dimethylsulfoxide-d6 (99.9\%, Sigma Aldrich), followed by analyzed with ${ }^{1} \mathrm{H}$ nuclear magnetic resonance $\left({ }^{1} \mathrm{H}\right.$ NMR) spectrometer (Bruker AVANCE III 500).

\subsection{Determination of hydrazine $\left(\mathrm{N}_{2} \mathrm{H}_{4}\right)$.}

The $\mathrm{N}_{2} \mathrm{H}_{4}$ was quantified according to the Watt and Chrisp method. ${ }^{6}$ Briefly, $5.99 \mathrm{~g}$ of $p$ dimethylaminobenzaldehyde ( $>99 \%$, Aladdin Chemistry) was dissolved in a mixed solution of $\mathrm{HCl}$ (concentrated, $30 \mathrm{~mL}$ ) and ethanol $(300 \mathrm{~mL})$, which was used as the color reagent. Then $5 \mathrm{~mL}$ of production solution was mixed with $5 \mathrm{~mL}$ of color reagent above. After aging for $20 \mathrm{~min}$ at $25{ }^{\circ} \mathrm{C}$, the absorbance of the mixed solution was determined by a UV-Vis spectrophotometer at a wavelength of $455 \mathrm{~nm}$. The standard curve was performed as follows. First, the standard solutions of hydrazine monohydrate (>99\%, Aladdin Chemistry) with known concentrations of 0,0.1,0.2, 0.4, 0.6, 0.8, and $1.0 \mu \mathrm{g} \mathrm{mL}-1$ were prepared. Then the standard curve was achieved by fitting the $\mathrm{N}_{2} \mathrm{H}_{4} \cdot \mathrm{H}_{2} \mathrm{O}$ concentrations versus corresponding absorbance value at $455 \mathrm{~nm}$. The obtained fitting curve showed good linear relation of absorbance with $\mathrm{N}_{2} \mathrm{H}_{4} \cdot \mathrm{H}_{2} \mathrm{O}$ concentration $\left(y=1.03 x+0.08, R^{2}=0.9994\right)$.

\subsection{Calculation of NRR Faradaic efficiency (FE) and $\mathrm{NH}_{3}$ yield rate.}

The FE of NRR was determined using the following equation: $\mathrm{FE}=(3 F \times C \times V) / 17 Q$, where $F$ is the Faraday constant $\left(96,485 \mathrm{C} \mathrm{mol}^{-1}\right), C$ is the ammonia concentration, $V$ is the volume of the production solution $(30 \mathrm{~mL})$, and $Q$ is the total charge passed through the electrode. The mass-normalized and areanormalized $\mathrm{NH}_{3}$ yield rates $\left(r\left(\mathrm{NH}_{3}\right)\right)$ were calculated using the equations of $r\left(\mathrm{NH}_{3}\right)=(C \times V) /(t \times m)$ 
and $r\left(\mathrm{NH}_{3}\right)=(C \times V) /(t \times A)$ respectively, where $C$ is the ammonia concentration, $V$ is the volume of the production solution $(30 \mathrm{~mL}), t$ is the reaction time $(2 \mathrm{~h}), m$ is the loading mass of the electrocatalysts $(0.2 \mathrm{mg})$, and $A$ is the area of the carbon paper $\left(1 \times 1 \mathrm{~cm}^{2}\right)$.

\subsection{In situ ATR-FTIR electrochemical measurements.}

ATR-FTIR experiments were performed on a Bruker INVENIO-R spectrometer equipped with a liquid nitrogen cooled mercury cadmium telluride (MCT) detector, a Veemax III ATR accessory (Kromatek), and a spectro-electrochemical cell (Figure S19). A Teflon cell was mounted onto a single bounce $60^{\circ} \mathrm{CaF}_{2}$ crystal. The corresponding electrochemical tests were performed on a $\mathrm{CHI} 760 \mathrm{E}$ electrochemistry workstation in a typical three-electrode configuration with a coiled $\mathrm{Pt}$ wire and $\mathrm{Ag} / \mathrm{AgCl}$ (saturated $\mathrm{KCl}$ electrolyte) electrode as the counter and reference electrodes, respectively. 10 $\mu \mathrm{L}$ of the catalyst ink was dropped on a Pt/C electrode with a geometric area of $0.28 \mathrm{~cm}^{2}$, obtaining the working electrode. The mass loading of catalyst on Pt/C electrode was calculated to be $0.14 \mathrm{mg} \mathrm{cm}^{-2}$. The $\mathrm{N}_{2}$ inlet and gas outlet were connected on both sides of the cell.

Before tests, the purified $\mathrm{N}_{2}$ was continuously purged into the methanol-water electrolyte $(0.16 \%$ of water volumetric content) in spectro-electrochemical cell for $30 \mathrm{~min}$ with a flow rate of $20 \mathrm{~mL} \mathrm{~min}^{-1}$. The flow rate of $\mathrm{N}_{2}$ was then changed to $10 \mathrm{~mL} \mathrm{~min}{ }^{-1}$ before the in situ ATR-FTIR measurements. After that, a background spectrum was collected, and the following spectra were performed by employing this background. The potentiostatic tests were then conducted with $100 \% i R$-compensation. Meanwhile, the in situ ATR-FTIR measurement was synchronously triggered with a resolution of 16 $\mathrm{cm}^{-1}$ in the range of $800-4000 \mathrm{~cm}^{-1}$ without atmospheric compensation, and corresponding spectra were recorded by the OPUS software. 


\section{Supporting Figures.}
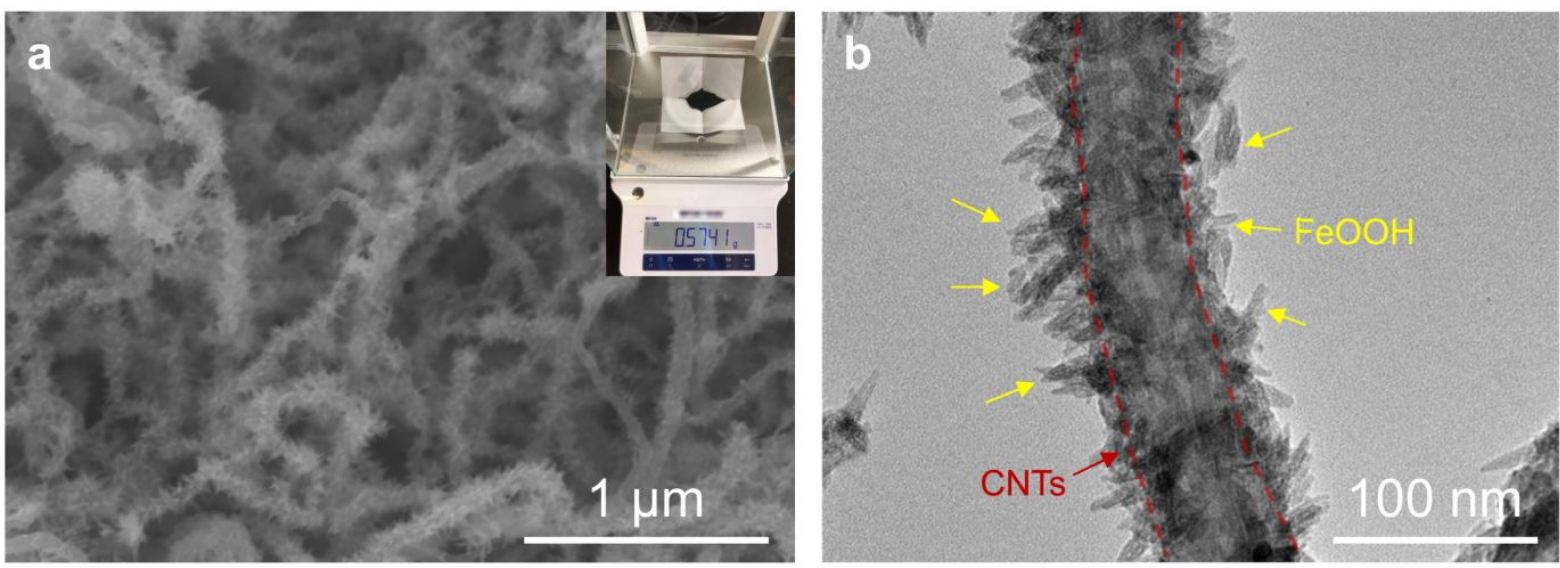

Figure S1. Morphology of FeOOH/CNTs. (a) SEM and (b) TEM images of the as-made $\mathrm{FeOOH} / \mathrm{CNT}$ s electrocatalyst. The inset of (a) is the optical picture of $\mathrm{FeOOH} / \mathrm{CNT}$ s electrocatalyst.

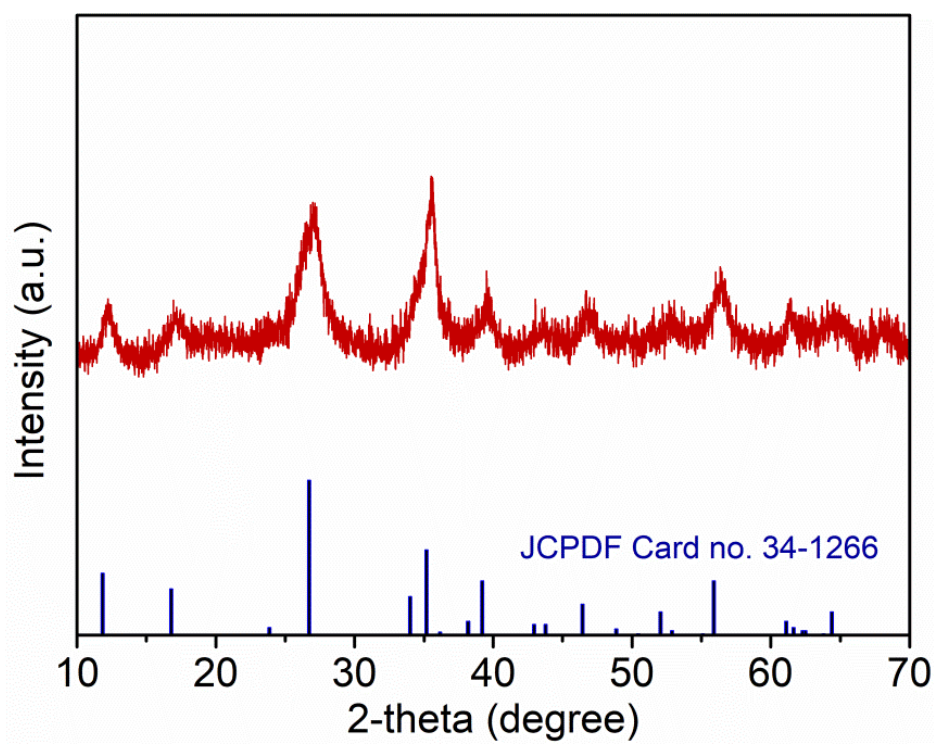

Figure S2. Structure characterization for FeOOH/CNTs. XRD pattern of FeOOH/CNTs. 

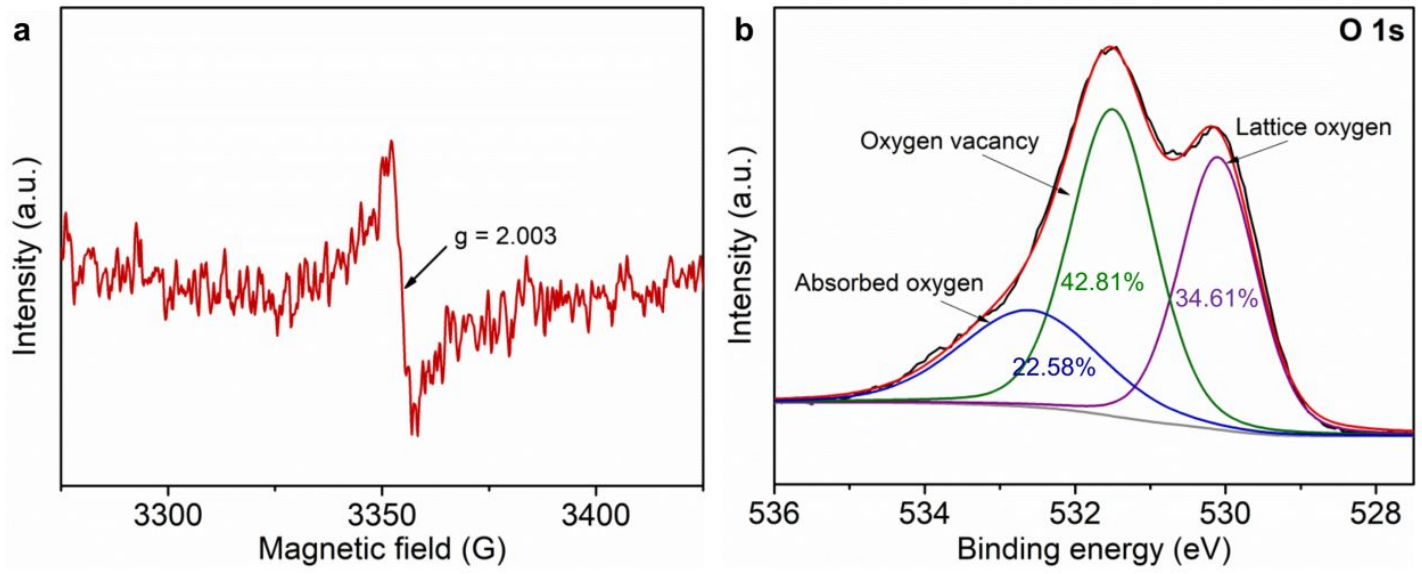

Figure S3. Analysis for the structure and chemical compositions of FeOOH/CNTs. (a) EPR spectrum of FeOOH/CNTs. (b) High-resolution XPS spectrum of O 1s for FeOOH/CNTs.

As shown in Figure S3a, a lone EPR signal is detected at a $g$-factor of 2.003, attributed to the oxygen vacancy in $\mathrm{FeOOH}$, which is in accord with the literature. ${ }^{1}$ As presented in Figure S3b, the deconvolution of $\mathrm{O} 1 \mathrm{~s}$ region by peak fitting for $\mathrm{FeOOH} / \mathrm{CNT}$ f further confirms the existence of the oxygen vacancy in $\mathrm{FeOOH}$, and the corresponding atomic content is $42.81 \%$. Previous reports have confirmed that the oxygen vacancy of electrocatalyst can effectively activate the inert $\mathrm{N}_{2}$ molecules and facilitate the NRR process. ${ }^{7-8}$ 


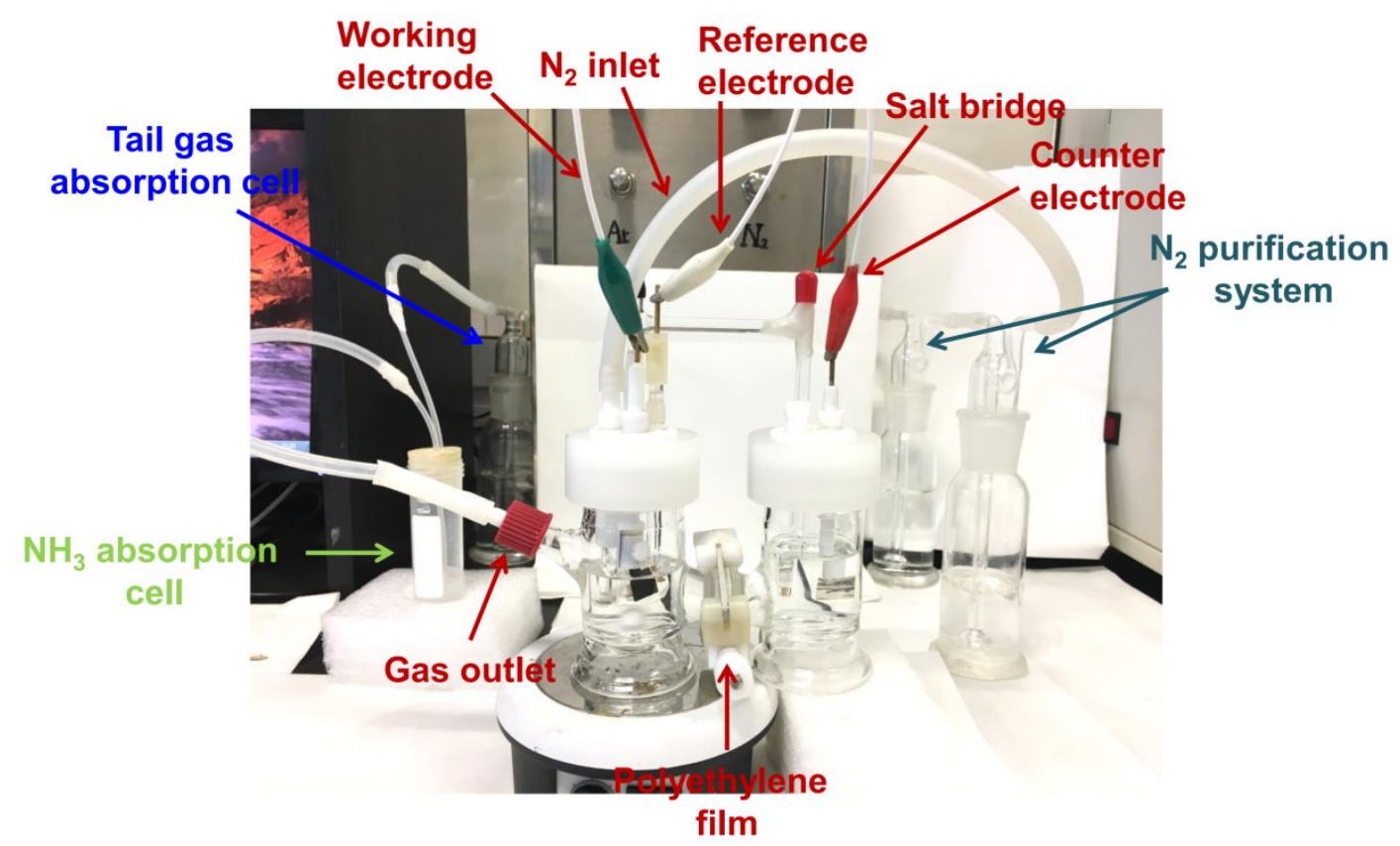

Figure S4. Photograph of the gas-tight electrocatalytic NRR device.

The two chambers were separated by a piece of polyethylene film with a thickness of $2 \mathrm{~mm}$ and connected by a salt bridge with saturated $\mathrm{KCl}$ solution. The feeding $\mathrm{N}_{2}$ was purified through two acidic absorption cells, in which the first absorption cell filled with $1 \mathrm{M} \mathrm{HCl}$ solution was used to absorb the possible $\mathrm{NH}_{3}$ in $\mathrm{N}_{2}$, and the second absorption cell filled with concentrated sulfuric acid was used to absorb the possible water vapor. The $\mathrm{NH}_{3}$ absorption cell $(1 \mathrm{M} \mathrm{HCl})$ can effectively absorb the escaped $\mathrm{NH}_{3}$ from the cathode cell. The tail gas absorption cell filled with deionized water was employed to separate the NRR device from the external environment. 


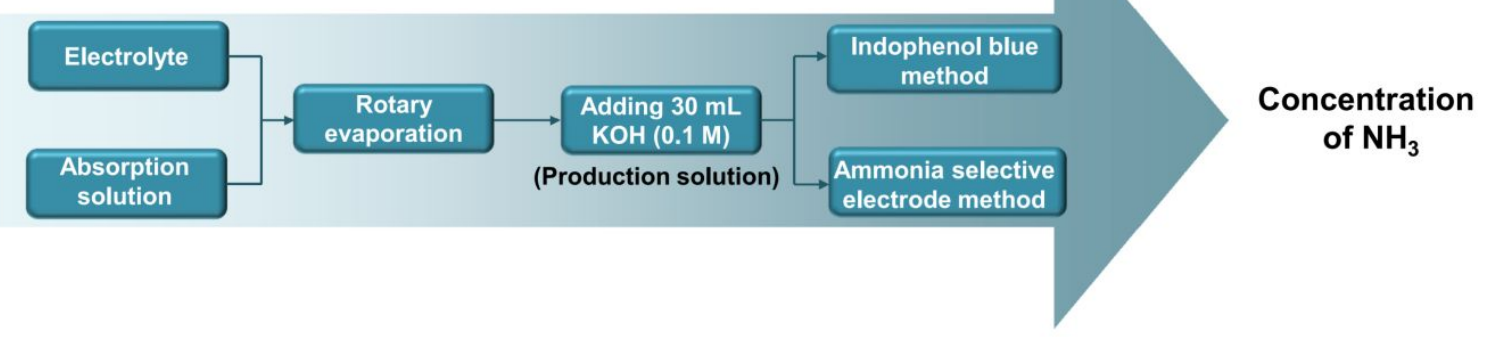

Figure S5. The detailed procedures for the quantification of $\mathrm{NH}_{3}$.

For a typical run, the post-reaction electrolyte of cathode cell and the absorption solution of absorption cell were subjected to rotary evaporation, yielding the $\mathrm{NH}_{4} \mathrm{Cl}$ product. After that, $30 \mathrm{~mL}$ of $0.1 \mathrm{M} \mathrm{KOH}$ solution was added into the rotary flask, obtaining the product solution. Finally, the $\mathrm{NH}_{3}$ concentration was determined by the indophenol blue and ammonia selective electrode methods.
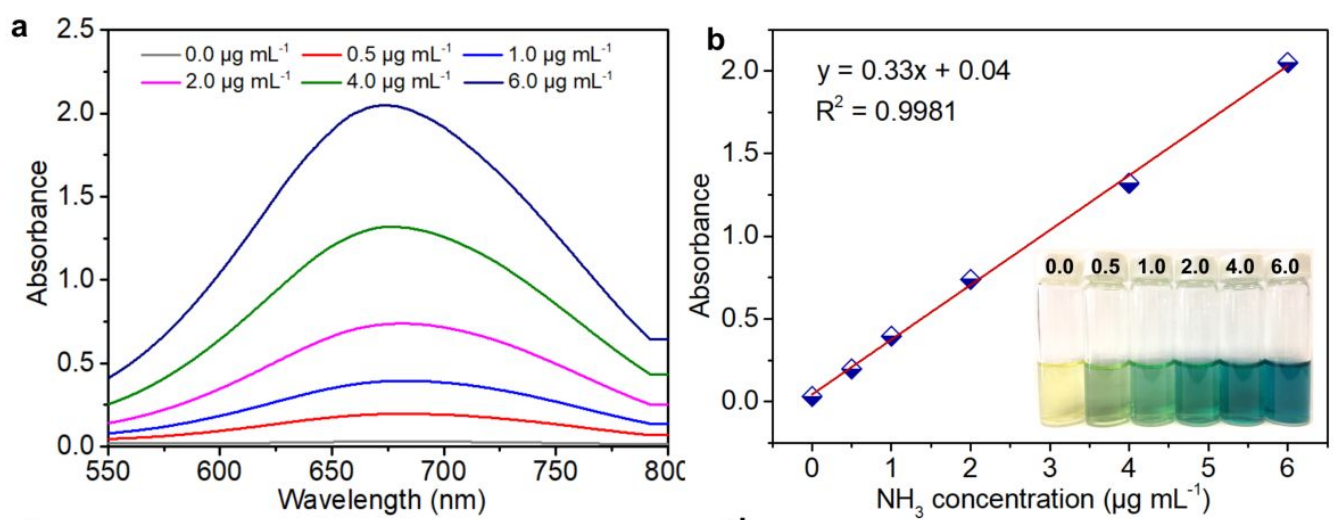

C
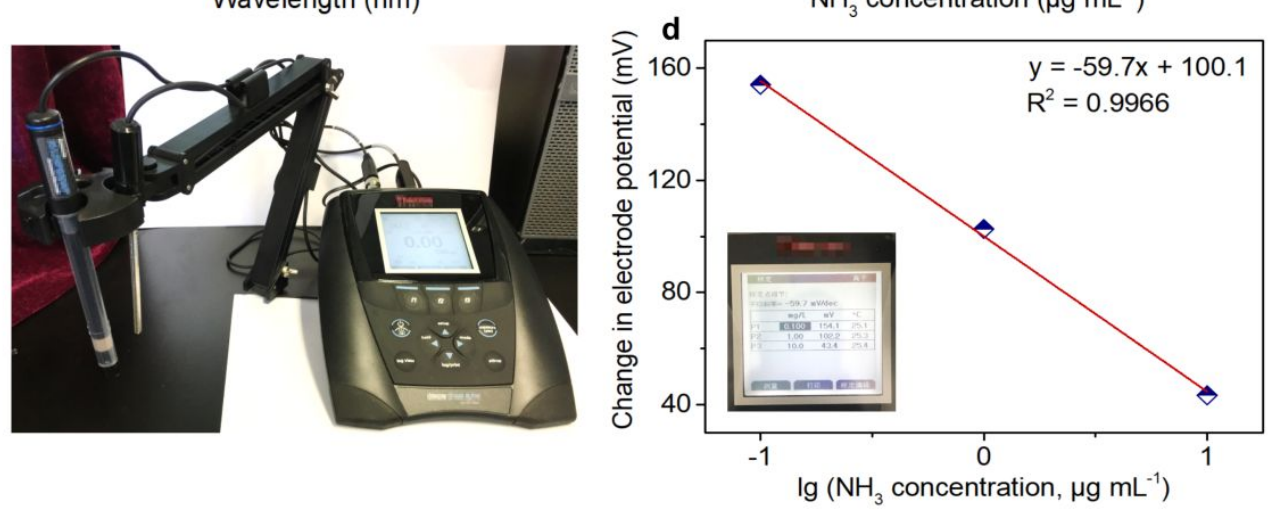

Figure S6. The methods for determining the amount of produced $\mathbf{N H}_{3}$. (a) UV-Vis absorption spectra for the standard $\mathrm{NH}_{3}$-containing solution with various $\mathrm{NH}_{3}$ concentrations and (b) corresponding calibration curve. (c) The picture of ammonia selective electrode and (d) corresponding calibration curve. The inset in (b) is the optical image of the standard $\mathrm{NH}_{3}$-containing solutions stained with indophenol indicator. 


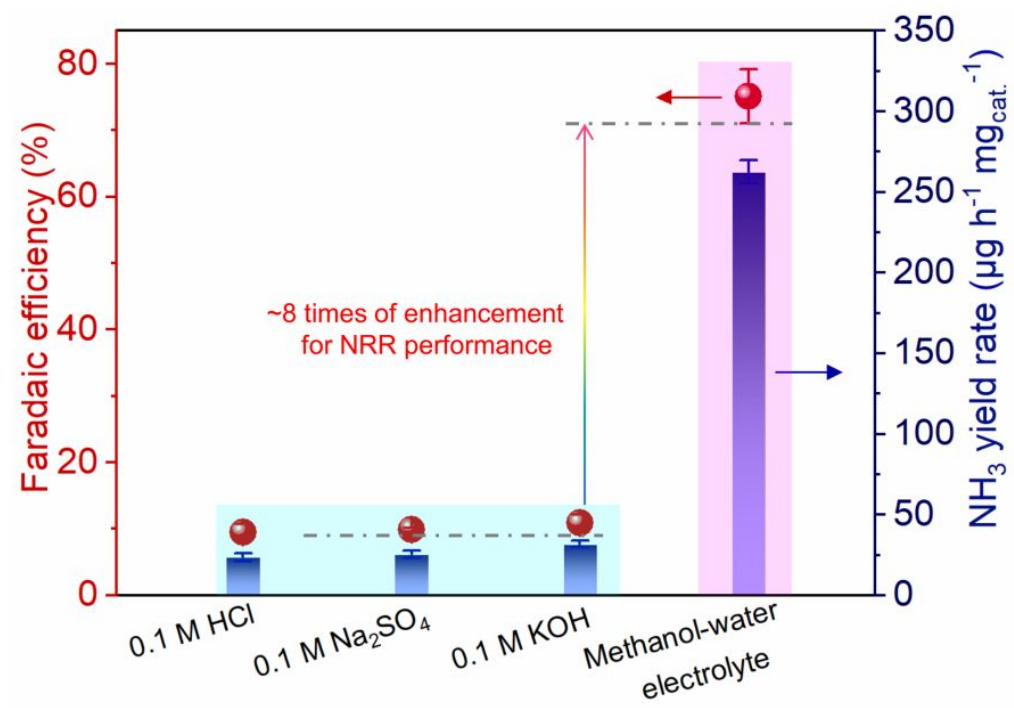

Figure S7. Comparison of NRR performance achieved by FeOOH/CNTs electrocatalyst in $0.1 \mathrm{M} \mathrm{HCl}$, $0.1 \mathrm{M} \mathrm{Na}_{2} \mathrm{SO}_{4}$, and $0.1 \mathrm{M} \mathrm{KOH}$ electrolytes. The water volumetric content in methanol-water electrolyte was $0.16 \%$.

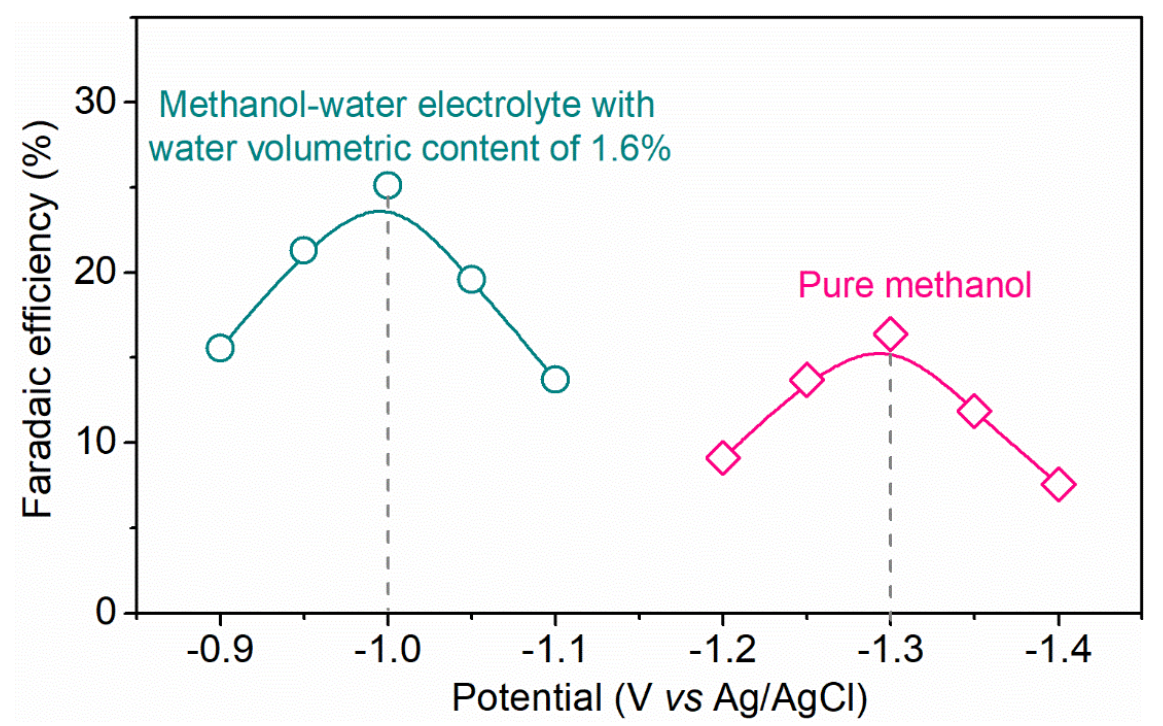

Figure S8. NRR FEs of FeOOH/CNTs at various applied potentials in methanol-water electrolyte with water volumetric content of $1.6 \%$ and pure methanol, respectively.

Obviously, the $\mathrm{FeOOH} / \mathrm{CNTs}$ achieves the maximum $\mathrm{FE}$ of $25.1 \%$ at applied potential of $-1.0 \mathrm{~V}$ in the methanol-water electrolyte, and achieves the maximum FE of $16.4 \%$ at the applied potential of -1.3 $\mathrm{V}$ in pure methanol electrolyte. 


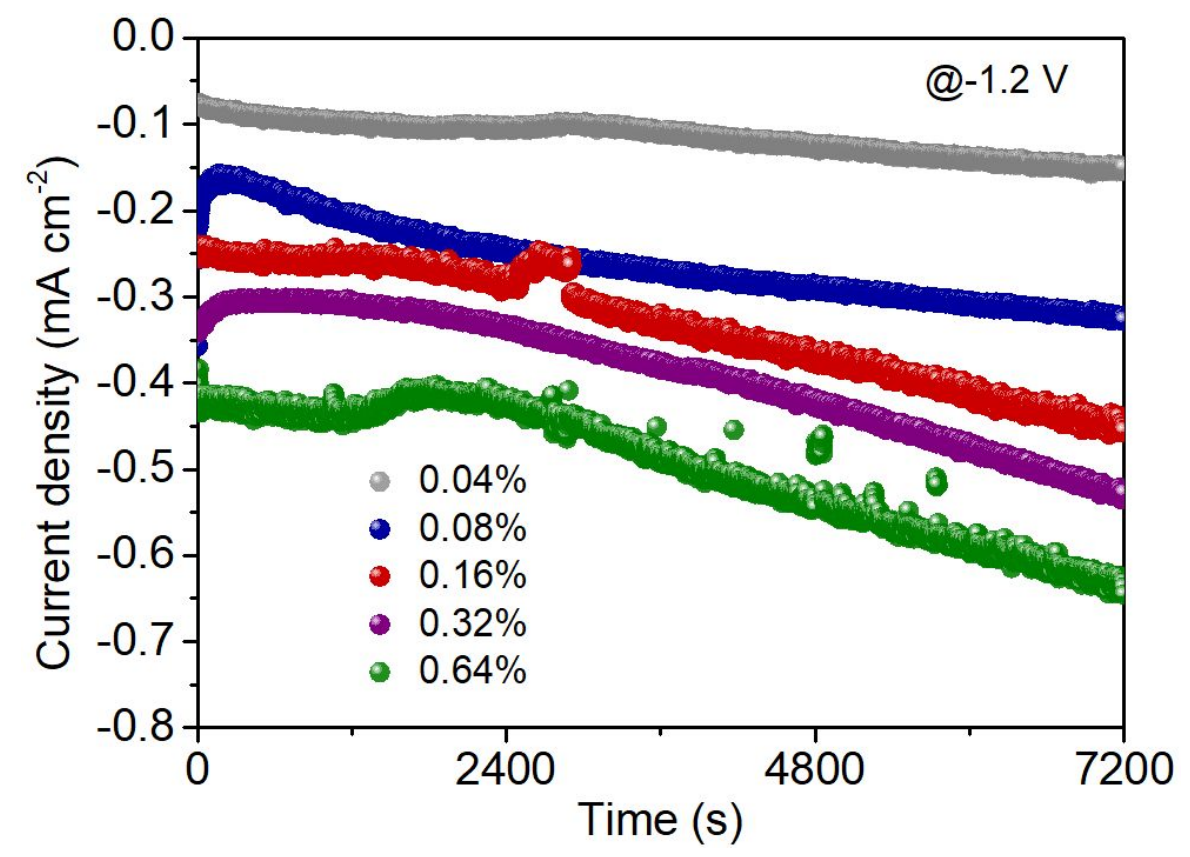

Figure S9. The variations of current density versus electrolysis time over FeOOH/CNTs in methanolwater electrolytes with different water volumetric content of $0.04,0.08,0.16,0.32$, and $0.64 \%$, respectively. 
a
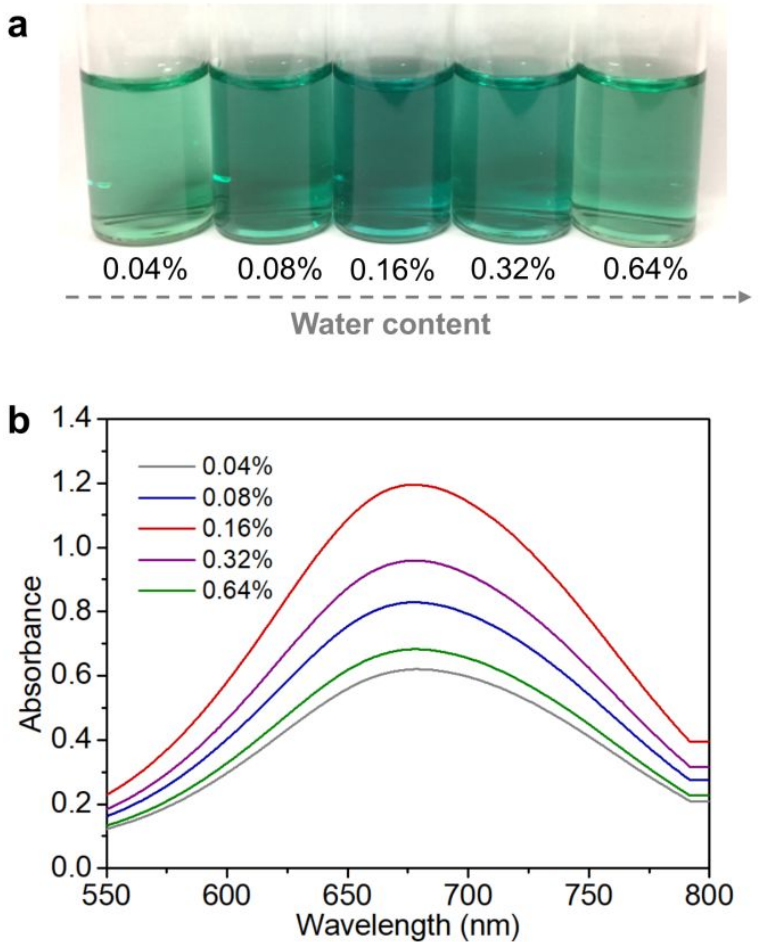

Figure S10. Effect of water volumetric content in methanol-water electrolyte on NRR performance over FeOOH/CNTs. Optical images (a) and corresponding UV-Vis absorption spectra (b) of the product solutions obtained after the potentiostatic test over $\mathrm{FeOOH} / \mathrm{CNTs}$ at $-1.2 \mathrm{~V} v \mathrm{sg} / \mathrm{AgCl}$ for $2 \mathrm{~h}$ in methanol-water electrolytes with water volumetric content of $0.04,0.08,0.16,0.32$, and $0.64 \%$ respectively, stained with indophenol indicator. 

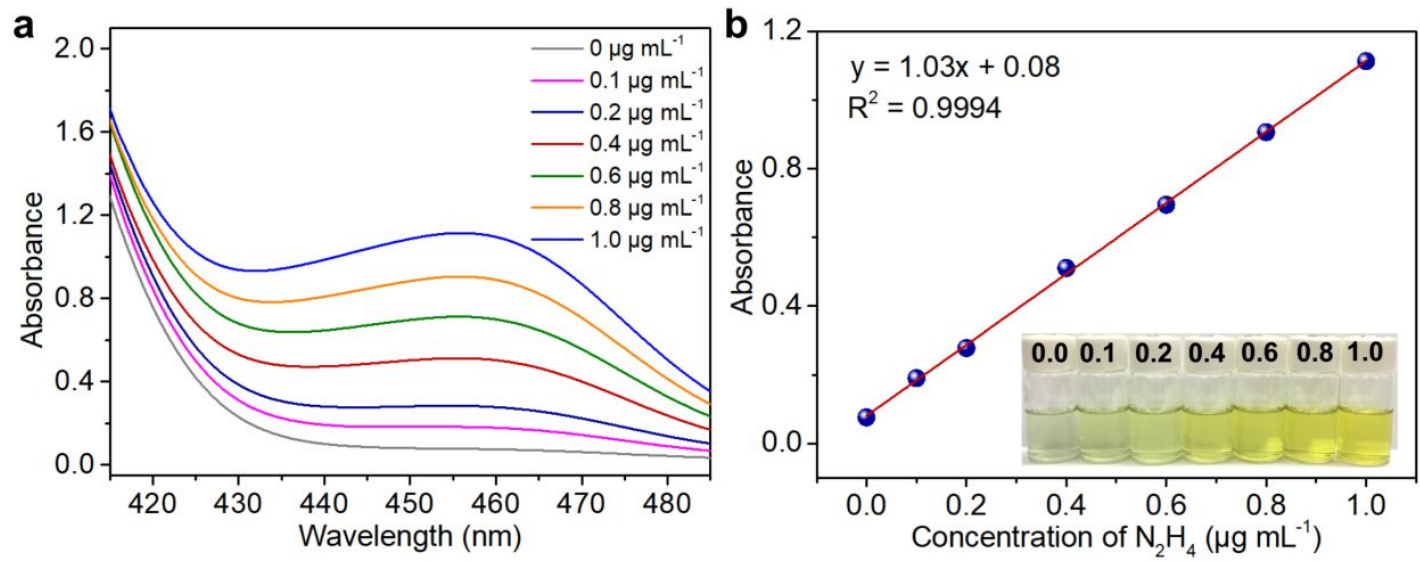

Figure S11. Method for determining the amount of hydrazine $\left(\mathbf{N}_{2} \mathbf{H}_{4}\right)$ byproduct. (a) UV-Vis spectra for standard solution of $\mathrm{N}_{2} \mathrm{H}_{4}$ with different concentrations and (b) corresponding calibration curve. The inset in (b) was the optical image of the standard $\mathrm{N}_{2} \mathrm{H}_{4}$-containing aqueous solutions stained with the chromogenic reagent.

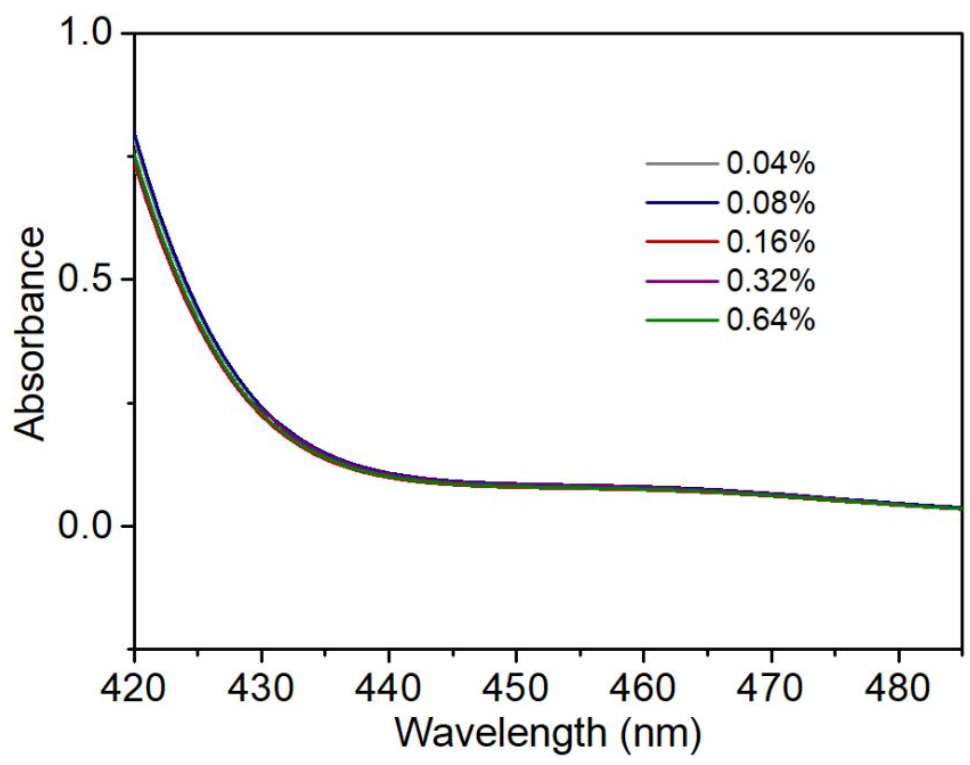

Figure S12. Determination for the possible $\mathbf{N}_{2} \mathbf{H}_{4}$ byproduct. UV-Vis spectra for the product solutions obtained over $\mathrm{FeOOH} / \mathrm{CNT}$ s electrocatalyst at an applied potential of $-1.2 \mathrm{~V}$ vs $\mathrm{Ag} / \mathrm{AgCl}$ in methanol-water electrolytes with various water volumetric contents of $0.04,0.08,0.16,0.32$, and $0.64 \%$, respectively, stained with the chromogenic reagent. 

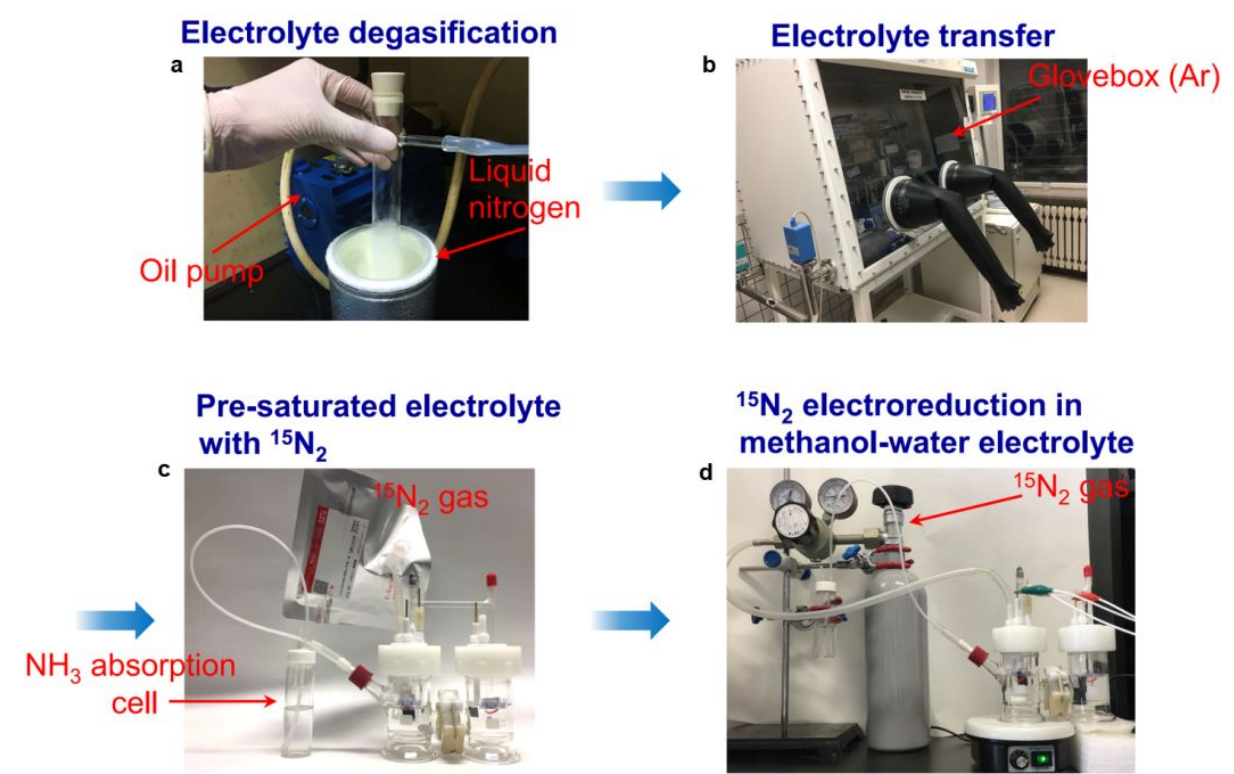

Figure S13. Procedures of NRR control experiment using isotopically labeled ${ }^{15} \mathrm{~N}_{2}$ as reaction gas, typically including electrolyte degasification (a), electrolyte transfer (b), pre-saturated electrolyte with ${ }^{15} \mathrm{~N}_{2}$ (c), ${ }^{15} \mathrm{~N}_{2}$ electroreduction in methanol-water electrolyte (d). 


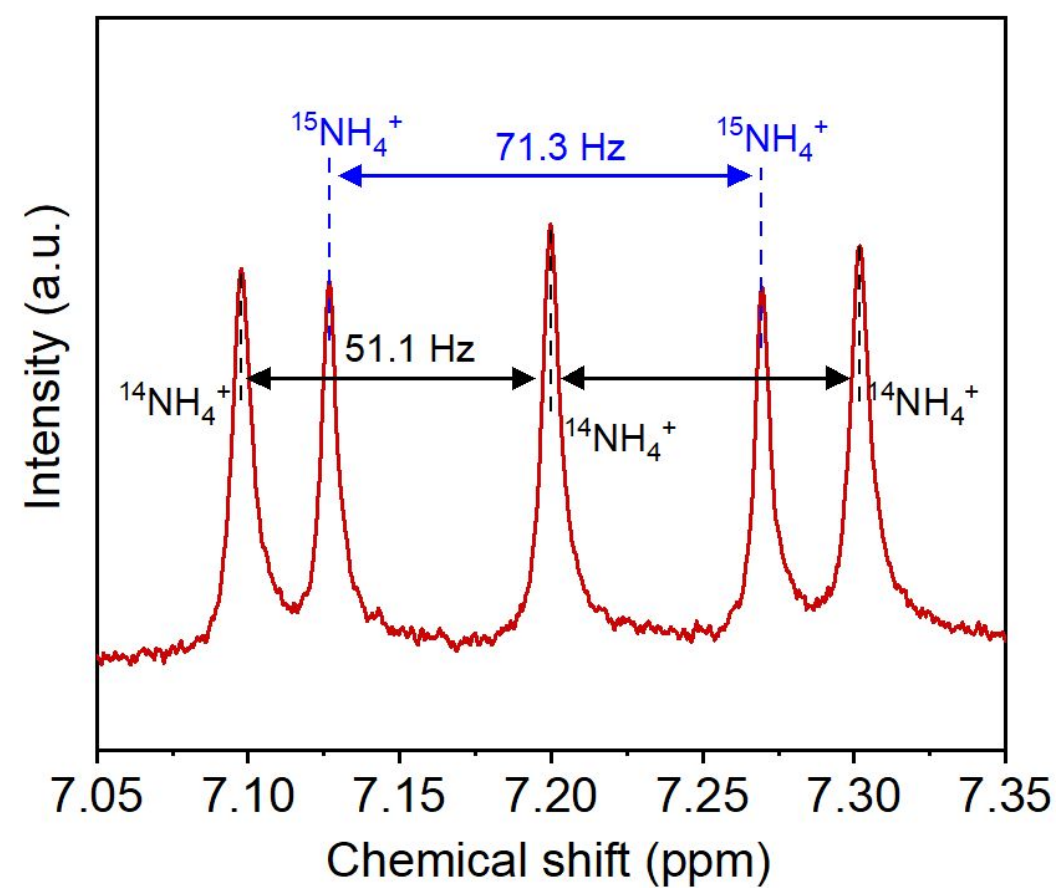

Figure S14. ${ }^{1} \mathrm{H}$ NMR spectrum of post-reaction electrolyte after the potentiostatic test at $-1.2 \mathrm{~V} v \mathrm{~s}$ $\mathrm{Ag} / \mathrm{AgCl}$ under ${ }^{15} \mathrm{~N}_{2}$ atmosphere. 


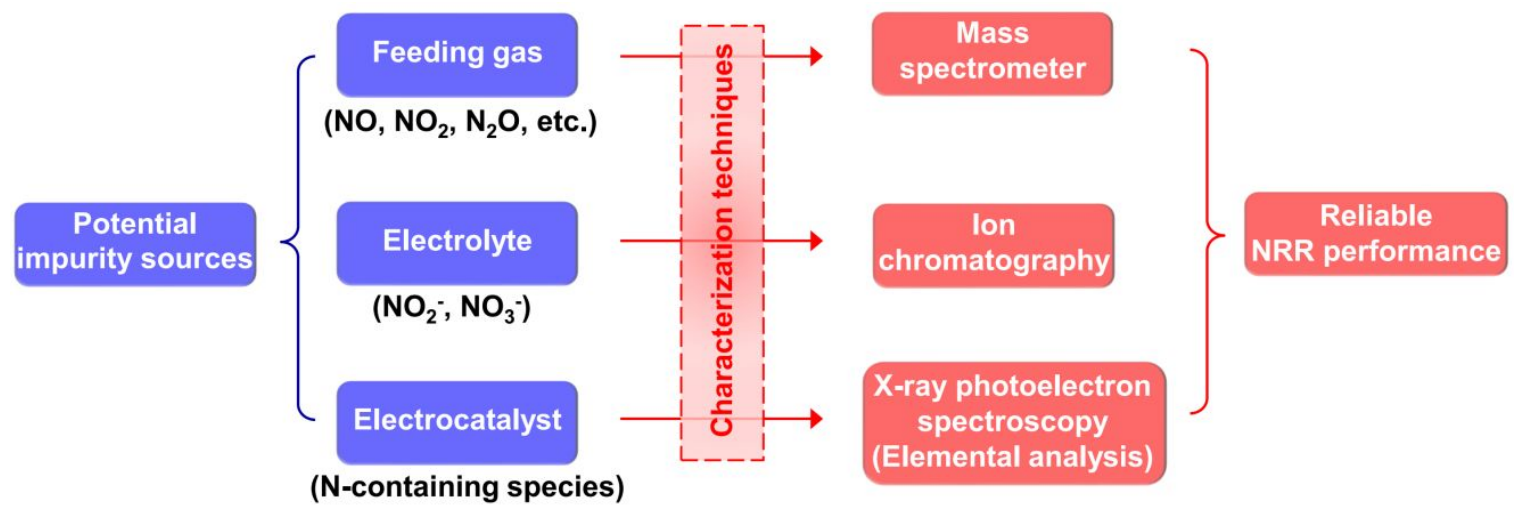

Figure S15. Schematic for how to exclude potential impurities during NRR process using advanced characterization techniques and to acquire the reliable NRR performance. 

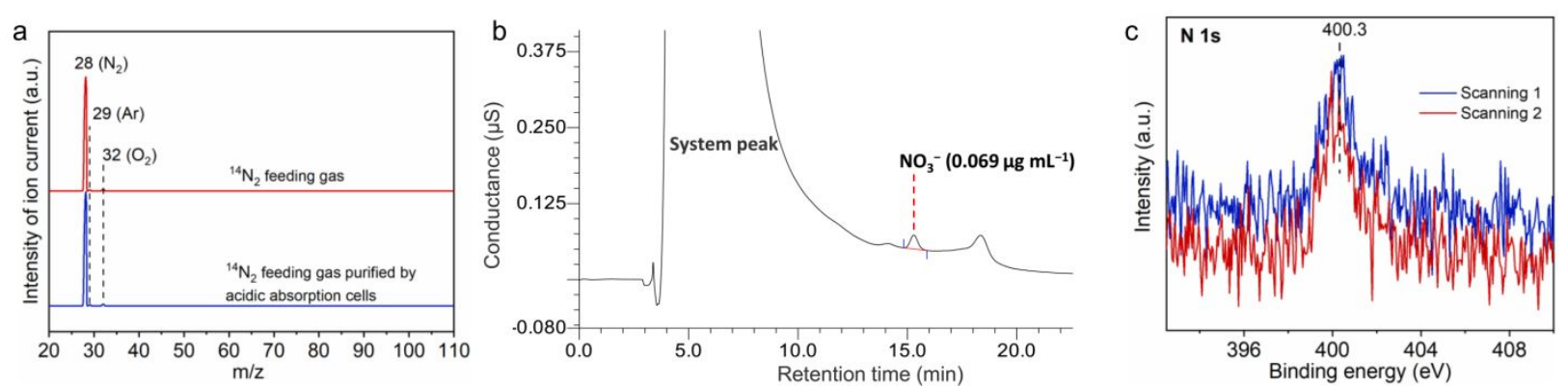

Figure S16. (a) Mass spectra for the used ${ }^{14} \mathrm{~N}_{2}$ feeding gas and the ${ }^{14} \mathrm{~N}_{2}$ feeding gas purified by the acidic absorption cells. (b) Ion chromatogram of $\mathrm{NO}_{3}{ }^{-}$and $\mathrm{NO}_{2}{ }^{-}$anions in commercial methanol. (c) $\mathrm{N}$ 1s spectra of $\mathrm{FeOOH} / \mathrm{CNTs}$, where the sample was scanned for two times.

At first, we employed the mass spectrometer to analyze the component of the ${ }^{14} \mathrm{~N}_{2}$ feeding gas. It can be seen from Figure S16a that, for both the ${ }^{14} \mathrm{~N}_{2}$ feeding gas and the ${ }^{14} \mathrm{~N}_{2}$ feeding gas purified by the two acidic absorption cells (containing $1 \mathrm{M} \mathrm{HCl}$ solution and concentrated sulfuric acid, respectively), a dominant peak with a m/z value of 28 and two negligible peaks with the $\mathrm{m} / \mathrm{z}$ values of 29 and 32 are identified, which are attributed to the ${ }^{14} \mathrm{~N}_{2}, \mathrm{Ar}$, and $\mathrm{O}_{2}$, respectively. The $\mathrm{N}_{\mathrm{x}} \mathrm{O}_{\mathrm{y}}$ impurities including $\mathrm{NO}$ $(\mathrm{m} / \mathrm{z}=30), \mathrm{N}_{2} \mathrm{O}(\mathrm{m} / \mathrm{z}=44), \mathrm{NO}_{2}(\mathrm{~m} / \mathrm{z}=46), \mathrm{N}_{2} \mathrm{O}_{3}(\mathrm{~m} / \mathrm{z}=76), \mathrm{N}_{2} \mathrm{O}_{4}(\mathrm{~m} / \mathrm{z}=92)$, and $\mathrm{N}_{2} \mathrm{O}_{5}(\mathrm{~m} / \mathrm{z}=108)$ are not be detected, which confirms that the ${ }^{14} \mathrm{~N}_{2}$ feeding gas used in the present work cannot introduce the $\mathrm{N}_{\mathrm{x}} \mathrm{O}_{\mathrm{y}}$ during NRR process.

Next, we used the ion chromatography to determine the concentrations of $\mathrm{NO}_{2}{ }^{-}$and $\mathrm{NO}_{3}{ }^{-}$anions within the commercial methanol (supreme anhydrous grade, Aladdin Chemistry), the corresponding spectrum is given in Figure S16b. It can be found that the $\mathrm{NO}_{3}{ }^{-}$is detected at the retention time of 15.29 min, and no $\mathrm{NO}_{2}{ }^{-}$is detected probably because it is easily oxidized in the air atmosphere. The concentration of $\mathrm{NO}_{3}{ }^{-}$is confirmed to be $0.069 \mu \mathrm{g} \mathrm{mL}^{-1}$. That is to say, even if all of the $\mathrm{NO}_{3}{ }^{-}$in electrolyte $(30 \mathrm{~mL})$ is reduced to $\mathrm{NH}_{3}(0.57 \mu \mathrm{g})$ during NRR process, the amount of $\mathrm{NH}_{3}$ is within the error of our measurements $( \pm 7.3 \mu \mathrm{g})$ and would not affect the accuracy of measurement for $\mathrm{NH}_{3}$ produced by NRR process.

With regard to $\mathrm{FeOOH} / \mathrm{CNTs}$ electrocatalyst, the X-ray photoelectron spectroscopy (XPS) and elemental analysis were employed to probe the surface N-containing species and corresponding content. As shown in Figure S16c, an extremely weak peak with binding energy of $400.3 \mathrm{eV}$ is detected in the $\mathrm{N}$ 1s spectrum of $\mathrm{FeOOH} / \mathrm{CNTs}$, indicative of the $\mathrm{C}-\mathrm{NH}$ component. 


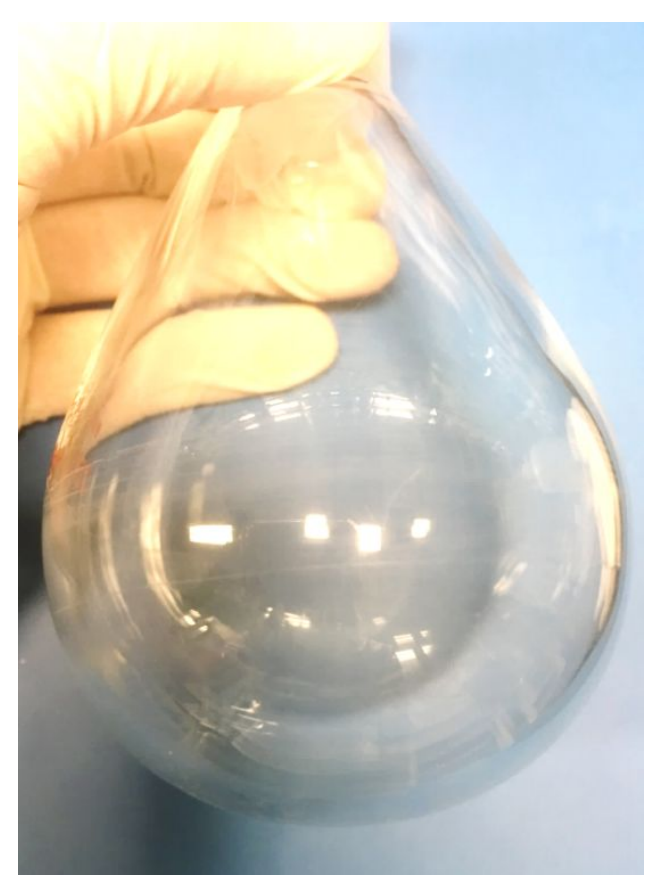

Figure S17. Optical image of the evaporated electrolyte obtained from the potentiostatic test for $2 \mathrm{~h}$ over $\mathrm{FeOOH} / \mathrm{CNTs}$ at $-1.2 \mathrm{~V}$ in methanol-water electrolyte with water volumetric content of $0.16 \%$ under Ar atmosphere.

Obviously, no visible amount of $\mathrm{NH}_{4} \mathrm{Cl}$ can be observed in the rotary flask after the potentiostatic test under $\mathrm{Ar}$ atmosphere, further confirming that $\mathrm{NH}_{3}$ was produced by the electrochemical NRR process.

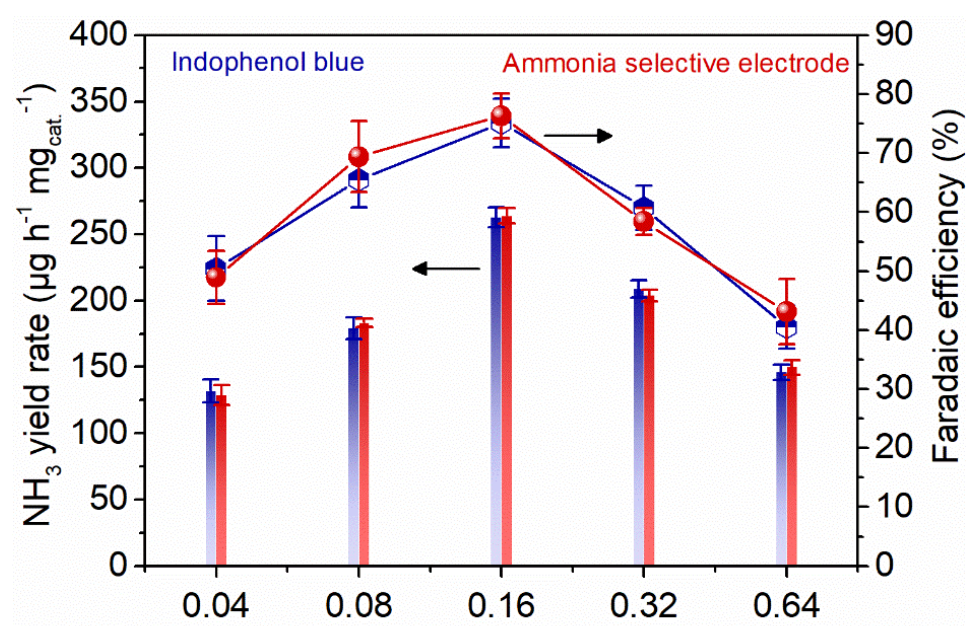

Water volumetric content of methanol-water electrolyte (\%)

Figure S18. The comparison of indophenol blue and ammonia selective electrode methods for measuring the $\mathrm{FEs}$ and $\mathrm{NH}_{3}$ yield rates. 


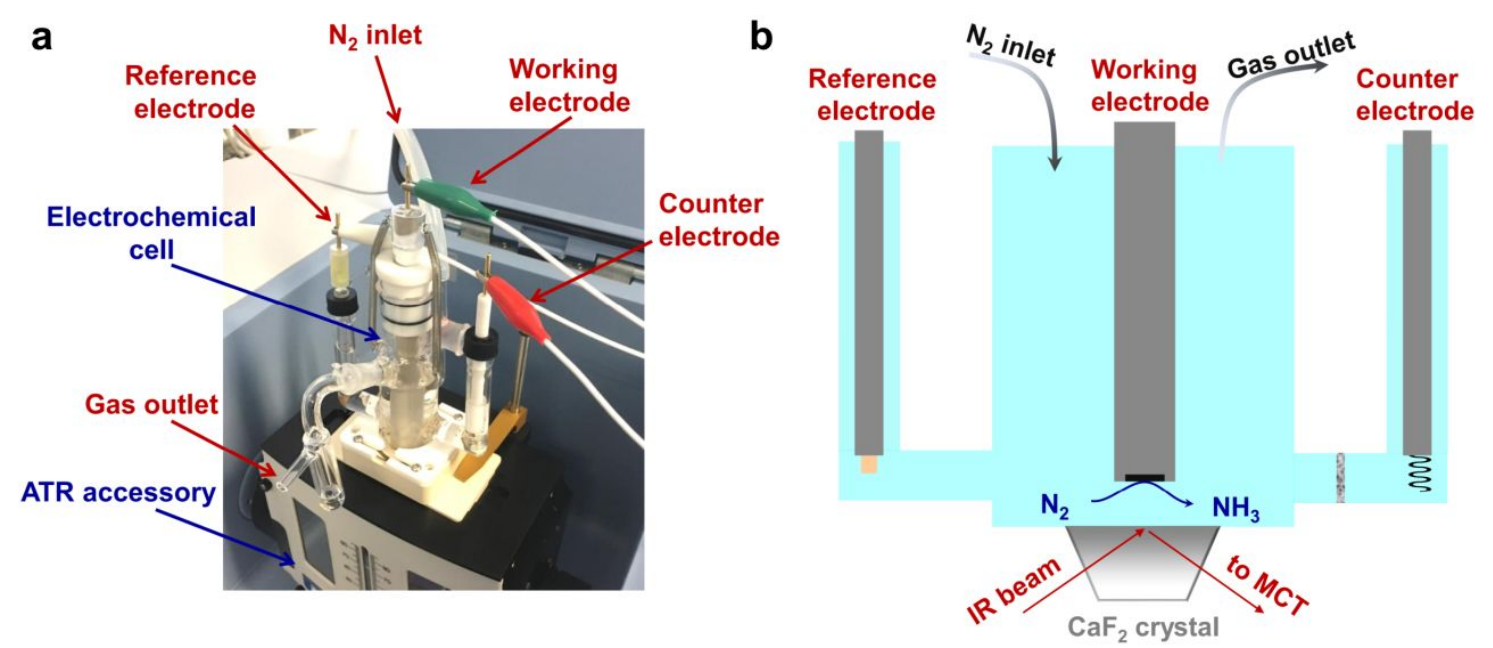

Figure S19. In situ electrochemical ATR-FTIR experiments. (a) The picture of the in situ electrochemical ATR-FTIR device. (b) Schematic diagram for the used spectro-electrochemical cell.

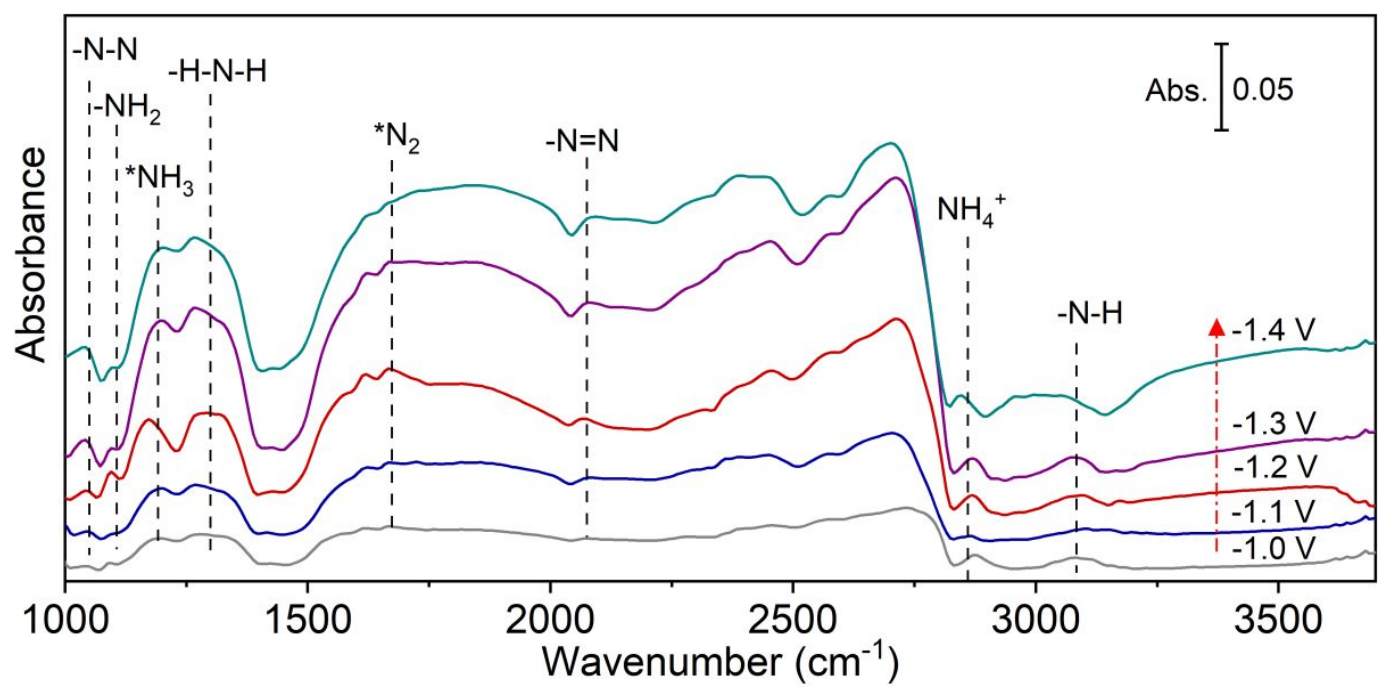

Figure S20. In situ electrochemical ATR-FTIR spectra over FeOOH/CNTs in methanol-water electrolyte with water volumetric content of $0.16 \%$ under $\mathrm{N}_{2}$ atmosphere after the potentiostatic tests for $100 \mathrm{~s}$ at the applied potentials of $-1.0,-1.1,-1.2,-1.3$, and $-1.4 \mathrm{~V} v \mathrm{Ag} / \mathrm{AgCl}$, respectively. 


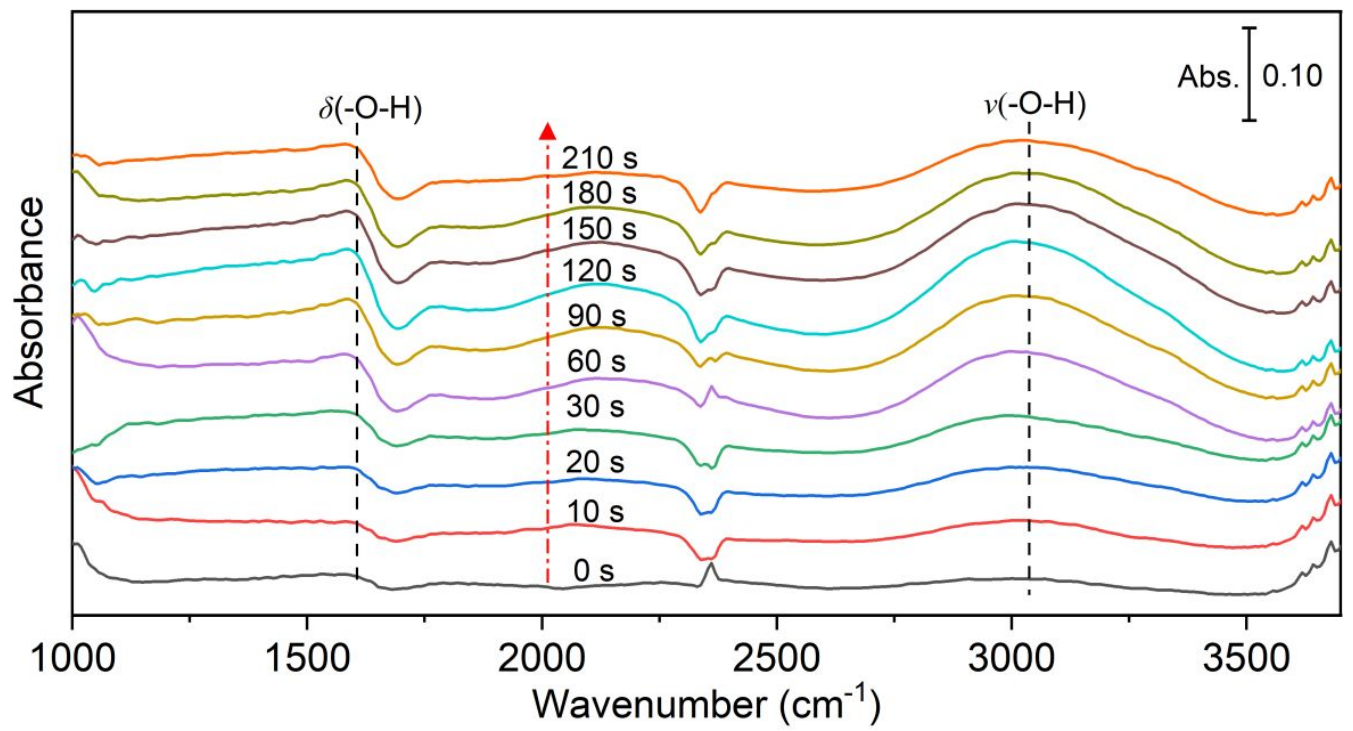

Figure S21. In situ electrochemical ATR-FTIR spectra over FeOOH/CNTs at $-1.2 \mathrm{~V}$ vs $\mathrm{Ag} / \mathrm{AgCl}$ in pure water electrolyte under $\mathrm{N}_{2}$ atmosphere.
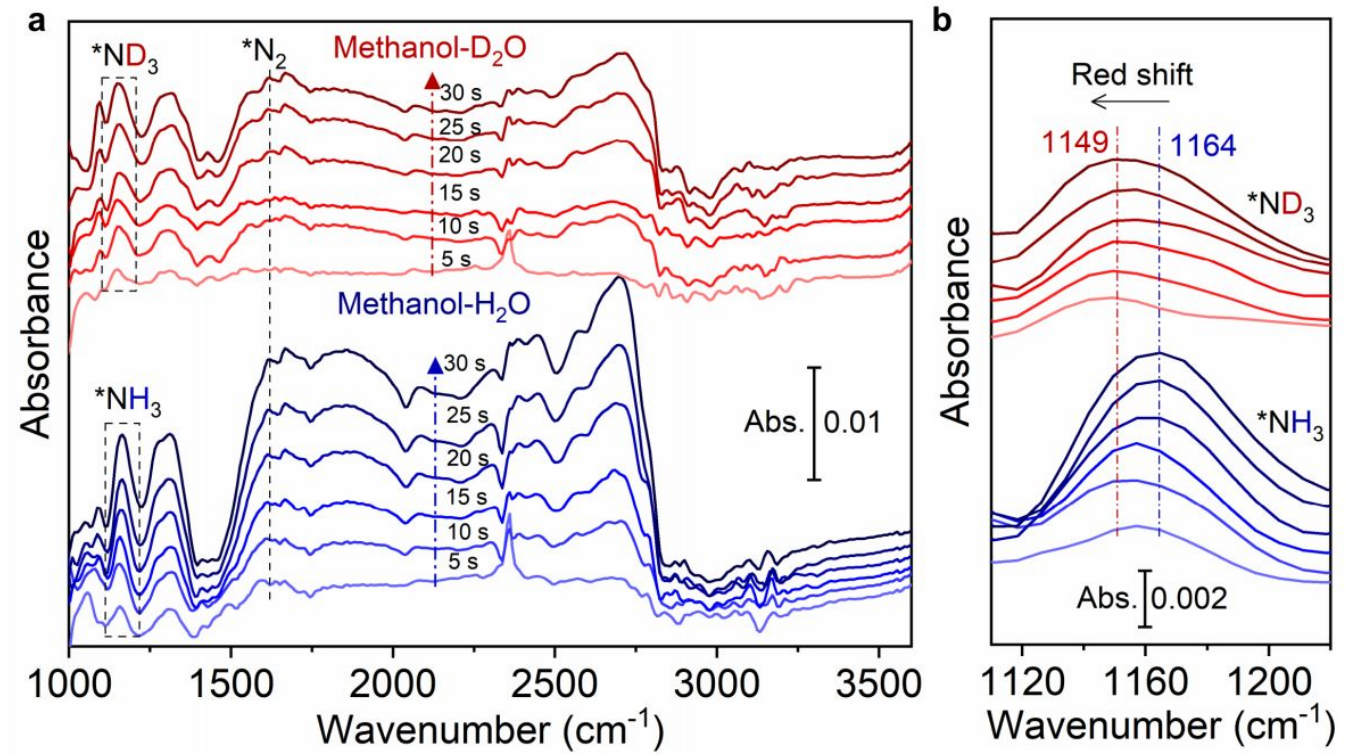

Figure S22. (a) Time-resolved in situ electrochemical ATR-FTIR spectra over FeOOH/CNTs at $-1.2 \mathrm{~V}$ vs $\mathrm{Ag} / \mathrm{AgCl}$ in methanol- $\mathrm{H}_{2} \mathrm{O}$ and methanol- $\mathrm{D}_{2} \mathrm{O}$ electrolytes with $\mathrm{H}_{2} \mathrm{O} / \mathrm{D}_{2} \mathrm{O}$ volumetric contents of $0.16 \%$ under $\mathrm{N}_{2}$ atmosphere. (b) Magnifying ATR-FTIR spectra for the $* \mathrm{NH}_{3}$ and $* \mathrm{ND}_{3}$ region. The stretching vibration peak of adsorbed $\mathrm{N}_{2}\left({ }^{*} \mathrm{~N}_{2}\right)$ remains unchanged after replacing the $\mathrm{H}_{2} \mathrm{O}$ with $\mathrm{D}_{2} \mathrm{O}$ (Figure S22a), whereas the stretching vibration peak of adsorbed $\mathrm{NH}_{3}\left({ }^{*} \mathrm{NH}_{3}\right)$ presents a typical red shift from 1164 to $1149 \mathrm{~cm}^{-1}$ (Figure S22b). 

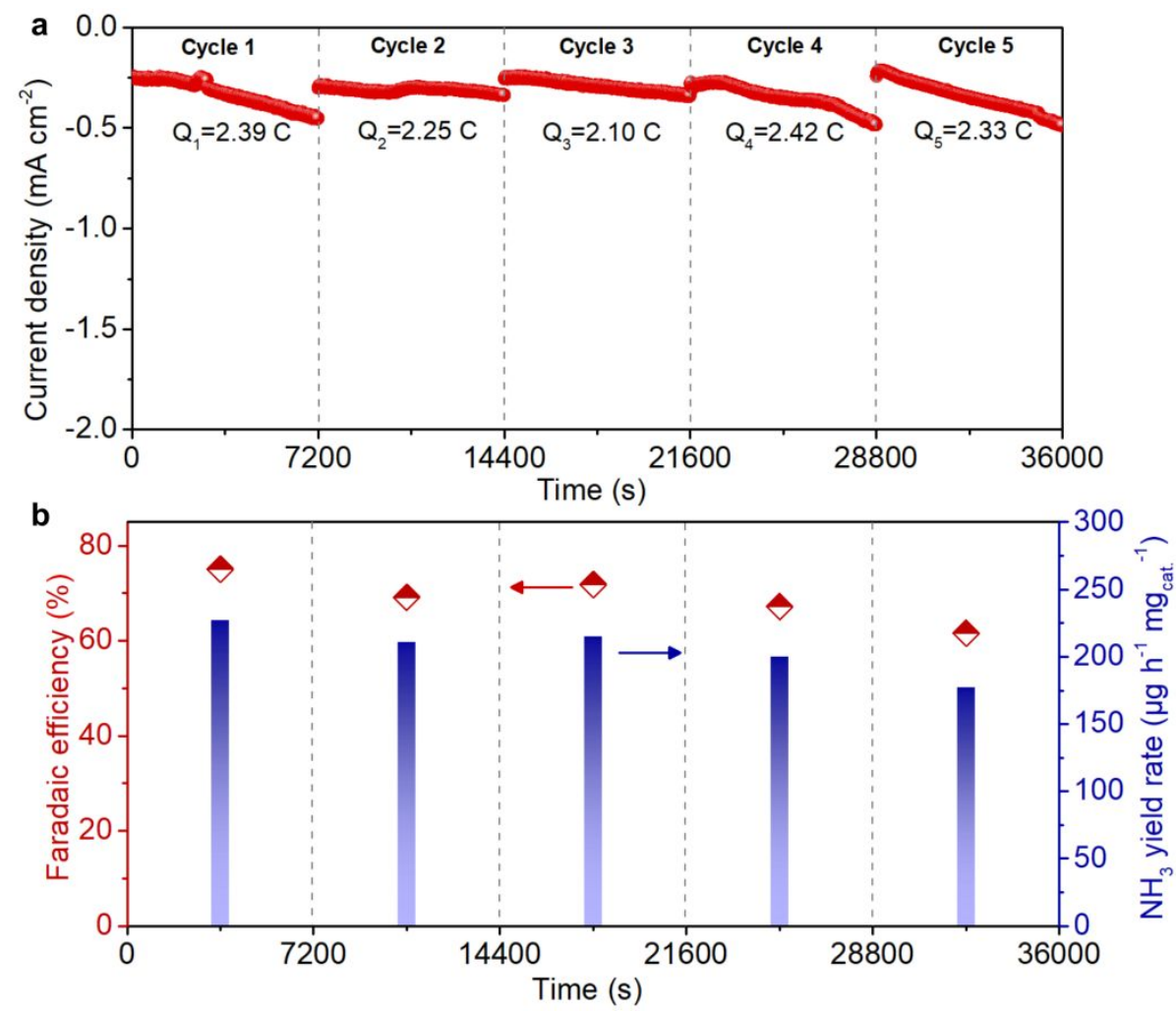

Figure S23. (a) The variations of current density versus electrolysis time over $\mathrm{FeOOH} / \mathrm{CNT}$ in a stability test recorded at $-1.2 \mathrm{~V}$ vs $\mathrm{Ag} / \mathrm{AgCl}$ in methanol-water electrolyte with the water volumetric content of $0.16 \%$. The FE of NRR can be determined according to the following equation: $\mathrm{FE}=(3 F \times C$ $\times V) / 17 Q$, where $F$ is the Faraday constant $\left(96,485 \mathrm{C} \mathrm{mol}^{-1}\right), C$ is the ammonia concentration, $V$ is the volume of the production solution $(30 \mathrm{~mL})$, and $Q$ is the total charge passed through the electrode. (b) Corresponding NRR $\mathrm{FE}$ and $\mathrm{NH}_{3}$ yield rate in the stability test. 


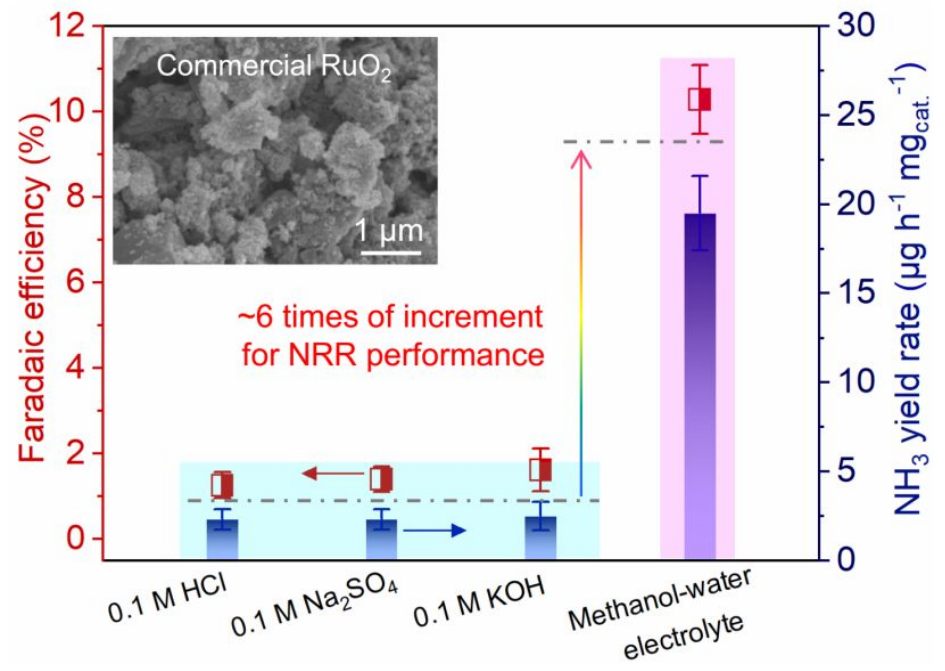

Figure S24. Comparison of NRR performance achieved by commercial $\mathrm{RuO}_{2}$ in aqueous electrolytes and the methanol-water electrolyte with water volumetric content of $0.16 \%$. The inset is the SEM image of $\mathrm{RuO}_{2}$. 

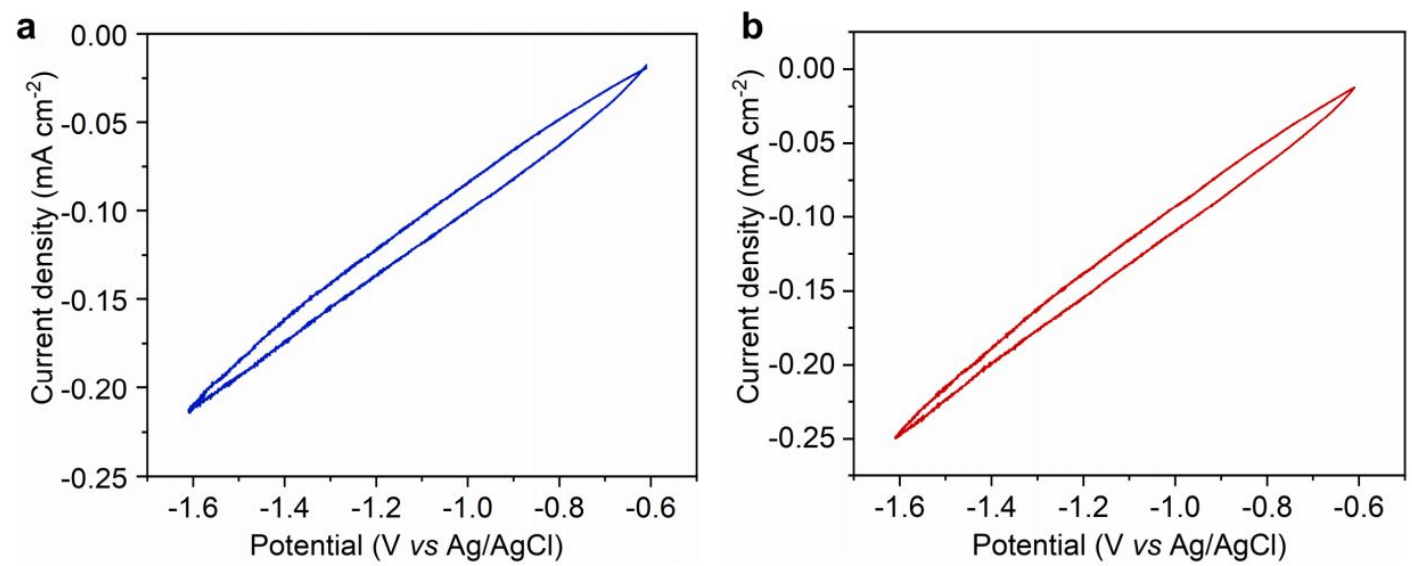

Figure S25. CV curves of FeOOH/CNTs electrocatalyst in pure methanol (a) and methanol-water electrolyte with water volumetric content of $0.16 \%$ (b) under $\mathrm{N}_{2}$ atmosphere. 


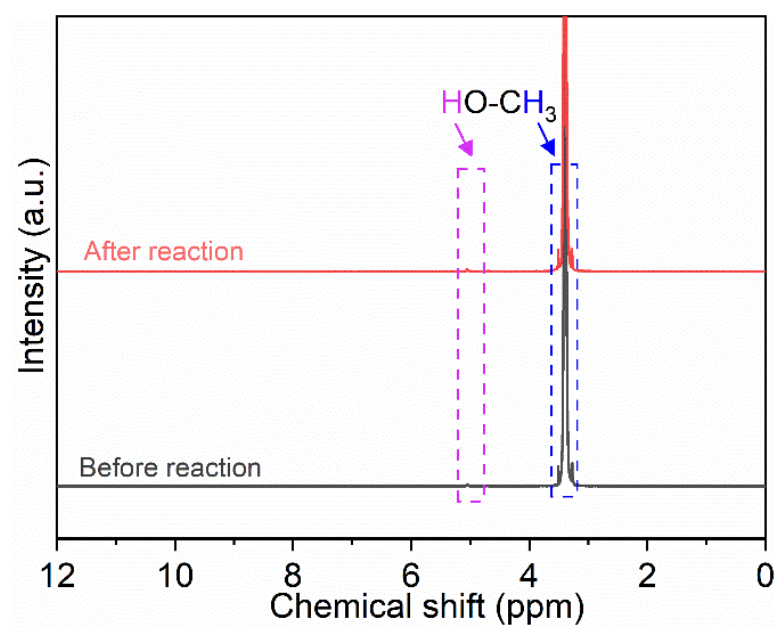

Figure S26. ${ }^{1} \mathrm{H}$ NMR spectra for the methanol-water electrolyte with water volumetric content of $0.16 \%$ before and after the potentiostatic test over $\mathrm{FeOOH} / \mathrm{CNT}$ electrocatalyst at $-1.2 \mathrm{~V} v \mathrm{sg} / \mathrm{AgCl}$ under $\mathrm{N}_{2}$ atmosphere for $4 \mathrm{~h}$.

For the original methanol-water electrolyte, the signals of methanol with the chemical shifts of 3.4 and $5.0 \mathrm{ppm}$ can be observed. After reaction, also only the signals of methanol can be detected, indicating that there are no methanol-derived liquid species formed during NRR process in the methanol-water electrolyte system. 
a

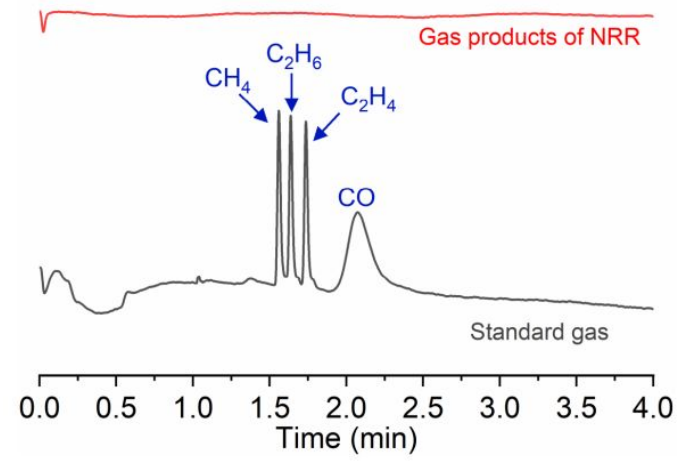

b

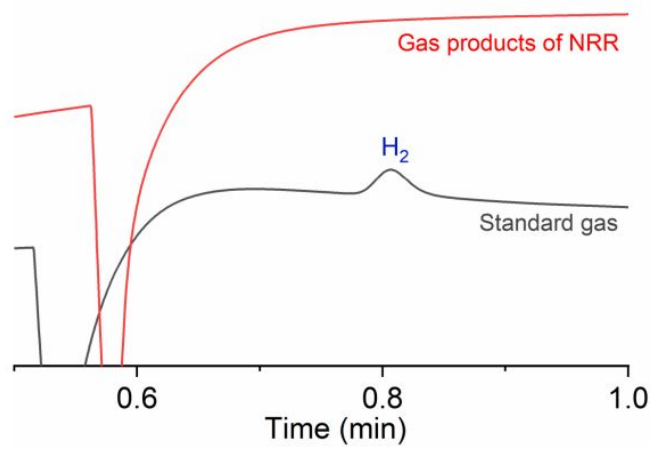

Figure S27. (a-b) The gas chromatograms for the standard gas and the gas products using gas chromatograph with thermal conductivity detector (TCD) and flame ionization detector (FID), respectively. The reaction was conducted in methanol-water electrolyte with water volumetric content of $0.16 \%$ over $\mathrm{FeOOH} / \mathrm{CNTs}$ electrocatalyst at $-1.2 \mathrm{~V} v s \mathrm{Ag} / \mathrm{AgCl}$ under $\mathrm{N}_{2}$ atmosphere.

As shown in Figure S27a, no signals of carbon monoxide $(\mathrm{CO})$ or hydrocarbons such as methane $\left(\mathrm{CH}_{4}\right)$, acetylene $\left(\mathrm{C}_{3} \mathrm{H}_{6}\right)$, and ethylene $\left(\mathrm{C}_{2} \mathrm{H}_{4}\right)$, etc. that may be derived from the decomposition/reaction of methanol can be detected, meaning that the methanol molecules are stable during NRR process. Meanwhile, it can be seen from Figure S27b that the signal of $\mathrm{H}_{2}$ is also not found, indicative of the greatly suppressed HER in the methanol-water electrolyte. 


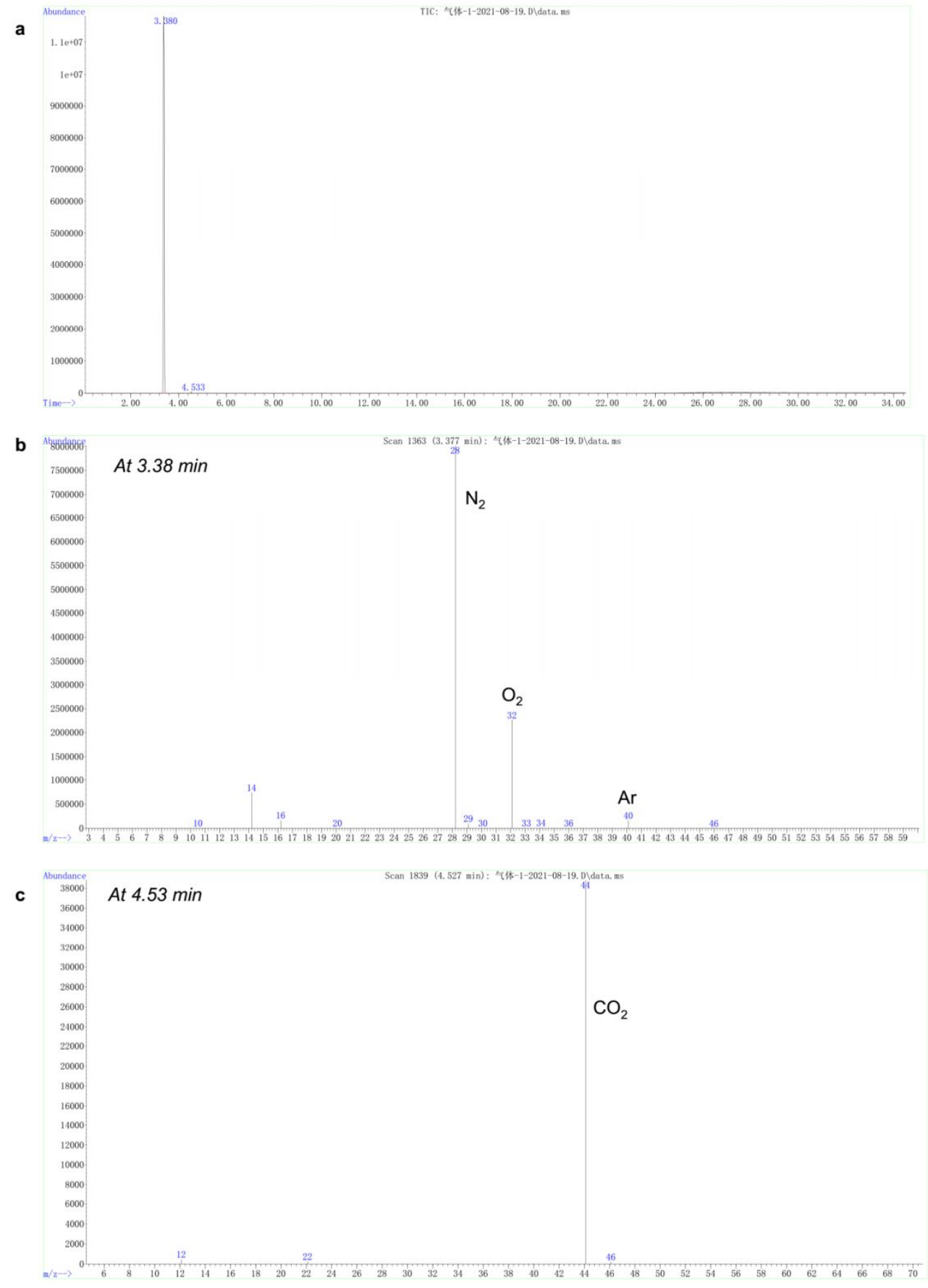

Figure S28. GC-MS analysis for the gas products. (a) The gas chromatogram (a) and corresponding mass spectra at retention time of 3.38 (b) and $4.53 \mathrm{~min}$ (c) for the gas products. The reaction was conducted in methanol-water electrolyte with water volumetric content of $0.16 \%$ over $\mathrm{FeOOH} / \mathrm{CNTs}$ electrocatalyst at $-1.2 \mathrm{~V} v s \mathrm{Ag} / \mathrm{AgCl}$ under $\mathrm{N}_{2}$ atmosphere.

As shown in Figure S28a, two signals including a strong signal at retention time of 3.38 min and a weak signal at retention time of $4.53 \mathrm{~min}$ are observed. Further, the corresponding mass spectra show that only the signals of $\mathrm{N}_{2}, \mathrm{O}_{2}, \mathrm{Ar}, \mathrm{CO}_{2}$, etc., that are attributed to the interference of air can be detected, and no signals of organic intermediates derived from methanol can be found (Figure S28b,c). 


\section{Supporting Table.}

Table S1. Elemental analysis for FeOOH/CNTs, in where the element contents of the sample was determined by repeating three-time experiment.

\begin{tabular}{lll}
\hline & Weight $(\mathrm{mg})$ & N content $(\mathrm{wt} \%)$ \\
\hline No. 1 & 2.1070 & 0.11 \\
No. 2 & 2.1010 & 0.10 \\
No. 3 & 2.1330 & 0.11 \\
\hline
\end{tabular}

The elemental analysis reveals that $\mathrm{N}$ content in FeOOH/CNTs is $\sim 0.11 \mathrm{wt} \%$. Therefore, even all the $\mathrm{N}$ species of FeOOH/CNTs $\left(0.2 \mathrm{mg}\right.$ used in each NRR test) was converted to $\mathrm{NH}_{3}(\sim 0.27 \mu \mathrm{g})$ during NRR process, this amount is also within the error of our measurements $( \pm 7.3 \mu \mathrm{g})$ and would not disturb the accuracy of evaluation for NRR performance in the proposed methanol-water electrolyte. 


\section{References}

(1) Zhang, B.; Wang, L.; Zhang, Y.; Ding, Y.; Bi, Y. Ultrathin FeOOH nanolayers with abundant oxygen vacancies on $\mathrm{BiVO}_{4}$ photoanodes for efficient water oxidation. Angew. Chem. Int. Ed. 2018, 57, $2248-2252$.

(2) Han, X.; Niu, Y.; Yu, C.; Liu, Z.; Huang, H.; Huang, H.; Li, S.; Guo, W.; Tan, X.; Qiu, J. Ultrafast construction of interfacial sites by wet chemical etching to enhance electrocatalytic oxygen evolution. Nano Energy 2020, 69, 104367.

(3) Hong, J.; Yu, C.; Song, X.; Meng, X.; Huang, H.; Zhao, C.; Han, X.; Wang, Z.; Qiu, J. Theoretical and experimental insights into the effects of oxygen-containing species within CNTs toward triiodide reduction. ACS Sustain. Chem. Eng. 2019, 7, 7527-7534.

(4) Ren, Y.; Yu, C.; Tan, X.; Han, X.; Huang, H.; Huang, H.; Qiu, J. Is it appropriate to use the Nafion membrane in electrocatalytic $\mathrm{N}_{2}$ reduction? Small Methods 2019, 3, 1900474.

(5) Lv, C.; Zhong, L.; Yao, Y.; Liu, D.; Kong, Y.; Jin, X.; Fang, Z.; Xu, W.; Yan, C.; Dinh, K. N.; Shao, M.; Song, L.; Chen, G.; Li, S.; Yan, Q.; Yu, G. Boosting electrocatalytic ammonia production through mimicking " $\pi$ back-donation”. Chem 2020, 6, 2690-2702.

(6) Liu, S.; Wang, M.; Qian, T.; Ji, H.; Liu, J.; Yan, C. Facilitating nitrogen accessibility to boron-rich covalent organic frameworks via electrochemical excitation for efficient nitrogen fixation. Nat.

Commun. 2019, 10, 3898.

(7) Yang, X.; Kattel, S.; Nash, J.; Chang, X.; Lee, J. H.; Yan, Y.; Chen, J. G.; Xu, B. Quantification of active sites and elucidation of the reaction mechanism of the electrochemical nitrogen reduction reaction on vanadium nitride. Angew. Chem. Int. Ed. 2019, 131, 13906-13910.

(8) Hirakawa, H.; Hashimoto, M.; Shiraishi, Y.; Hirai, T. Photocatalytic conversion of nitrogen to ammonia with water on surface oxygen vacancies of titanium dioxide. J. Am. Chem. Soc. 2017, 139, 10929-10936. 